\title{
Generic Global Solutions of the Relativistic Vlasov-Maxwell System of Plasma Physics
}

\section{Gerhard Rein}

Mathematisches Institut der Universität München, Theresienstraße 39, W-8000 München 2, Federal Republic of Germany

Received January 30, 1990

\begin{abstract}
The behaviour of classical solutions of the relativistic Vlasov-Maxwell system under small perturbations of the initial data is investigated. First it is shown that the solutions depend continuously on the initial data with respect to various norms. The main result is on global solutions: A global solution whose electromagnetic field decays in a certain way for large times is shown to remain global under small perturbations of the initial data and to retain the decay behaviour of the field. Therefore, such global solutions are generic. This result implies the existence of global solutions for nearly symmetric initial data.
\end{abstract}

\section{Introduction}

Consider a collisionless plasma with $N$ different species of particles, where a particle of species $\alpha$ has rest mass $m_{\alpha}$ and charge $e_{\alpha}$. Each species is described by a particle density $f_{\alpha}(t, x, v)$, where $t \geqq 0$ denotes time, $x \in \mathbb{R}^{3}$ position, and $v \in \mathbb{R}^{3}$ momentum. The particles may move at relativistic speeds and are assumed to interact only by the electromagnetic forces they create themselves so that the density functions $\left(f_{\alpha}\right)_{\alpha=1}^{N}=f$ together with the selfconsistent electromagnetic fields $E_{f}$ and $B_{f}$ evolve according to the relativistic Vlasov-Maxwell system (RVM):

$$
\begin{aligned}
\partial_{t} f_{\alpha}+\hat{v}_{\alpha} \cdot \partial_{x} f_{\alpha}+e_{\alpha}\left(E_{f}+\hat{v}_{\alpha} \times B_{f}\right) \cdot \partial_{v} f_{\alpha} & =0, & 1 \leqq \alpha \leqq N, \\
\partial_{t} E_{f}-\operatorname{curl} B_{f}=-4 \pi j_{f}, & & \operatorname{div} E_{f}=4 \pi \rho_{f}, \\
\partial_{t} B_{f}+\operatorname{curl} E_{f}=0, & & \operatorname{div} B_{f}=0 .
\end{aligned}
$$

Here

$$
\rho_{f}(t, x):=\sum_{\alpha=1}^{N} e_{\alpha} \int f_{\alpha}(t, x, v) d v
$$

and

$$
j_{f}(t, x):=\sum_{\alpha=1}^{N} e_{\alpha} \int \hat{v}_{\alpha} f_{\alpha}(t, x, v) d v
$$


denote the total charge and current densities, and

$$
\hat{v}_{\alpha}:=\frac{v}{\sqrt{m_{\alpha}^{2}+v^{2}}}
$$

is the relativistic speed of a particle of species $\alpha$ with momentum $v$ where the speed of light is assumed to be 1 .

We are interested in the corresponding initial value problem; that is, we impose initial conditions

$$
f(0)=\stackrel{\circ}{f}, \quad E_{f}(0)=\stackrel{\circ}{E_{f}}, \quad B_{f}(0)=\stackrel{\circ}{B}_{f},
$$

where the data have to satisfy the compatibility conditions

$$
\operatorname{div} \stackrel{\circ}{E}_{f}=4 \pi \stackrel{\circ}{\rho}_{f}, \quad \operatorname{div} \stackrel{\circ}{B}_{f}=0 .
$$

Throughout this paper solutions are always classical solutions; that is, $f, E_{f}$, and $B_{f}$ are $C^{1}$ with respect to all variables and satisfy the equations in the classical sense.

The purpose of this paper is to investigate the behaviour of classical solutions of RVM under small perturbations of the initial data. First we consider local solutions, obtaining results on continuous dependence on the initial data in various norms. Then we consider a class of global solutions exhibiting a certain asymptotic behaviour of the fields for large times. It is shown that the asymptotic behaviour of these solutions is stable under small perturbations of the initial data; that is, the perturbed solution remains global and retains its asymptotic behaviour. This general result applies to spherically symmetric solutions implying global existence for nearly symmetric data and extending Schaeffer's results from the case of the Vlasov-Poisson system to the relativistic Vlasov-Maxwell system, cf. [14].

Before going into more detail a brief survey of the known results on RVM may be useful. Glassey and Strauss [6] showed that a local solution is actually global, if the momenta remain bounded on its interval of existence. By establishing the required bound on the momenta, Glassey, Schaeffer, and Strauss proved global existence for small data [8] and for nearly neutral data [5]. For further results on RVM and related problems see the references.

If $B_{f}=0$ and Maxwell's equations are replaced by Poisson's equation for the potential of $E_{f}$, the resulting system is known as the relativistic Vlasov-Poisson system RVP; by further replacing $\hat{v}_{\alpha}$ by $v$ one obtains the Vlasov-Poisson system VP. For results on VP and RVP see the references. Schaeffer [15] proved that as the speed of light tends to infinity, the corresponding solutions of RVM tend to solutions of VP.

With some minor modifications the results of the present paper also hold for VP and RVP, while the proofs are greatly simplified by the fact that Poisson's equation is elliptic and much easier to analyse than the hyperbolic Maxwell system.

The paper is organized as follows: In the next section we state and briefly discuss the main results. For easier reference we collect a few known results on RVM in the third section. In the fourth section local perturbation is investigated, while the fifth section is devoted to global perturbation. 


\section{Main Results}

For easier reference, we now state and briefly discuss our main results, postponing the proofs to later sections. To this end we need some notation. For an interval $I \subset \mathbb{R}$ define

$$
\begin{aligned}
& C^{+}(I):=\{C: I \rightarrow] 0, \infty[\mid C \text { continuous and increasing }\}, \\
& C^{-}(I):=\{C: I \rightarrow[0, \infty[\mid C \text { continuous and decreasing }\} .
\end{aligned}
$$

For a solution $\left(f, E_{f}, B_{f}\right)$ define $K_{f}:=\left(E_{f}, B_{f}\right)$. Initial data will be taken from the following class:

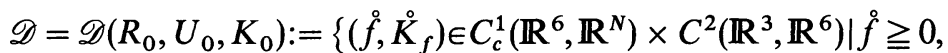

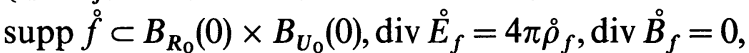

$$
\begin{aligned}
& \left.\left|\partial_{x}^{i} K_{f}(x)\right| \leqq K_{0}\left(1+R_{0}+|x|\right)^{-2-i}, i=0,1,2, x \in \mathbb{R}^{3}\right\} \text {, }
\end{aligned}
$$

where $R_{0}>0, U_{0}>0$, and $K_{0}>0$, and $B_{r}(z):=\left\{y \in \mathbb{R}^{3}|| y-z \mid<r\right\}$.

It follows from [6] that for each $\left(\stackrel{f}{f}, \dot{K}_{f}\right) \in \mathscr{D}$ there exists a unique, classical solution $\left(f, K_{f}\right)$ of the corresponding initial value problem on a maximal interval of existence which we denote by $\left[0, T\left(f, K_{f}\right)[\right.$.

Consider $\left(\stackrel{\circ}{g}, K_{g}\right) \in \mathscr{D}$. In order to study the behaviour of the solution $\left(g, K_{g}\right)$ corresponding to these initial data under perturbation of the data, define

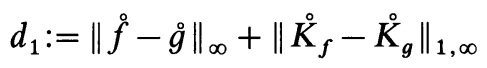

for $\left(f, K_{f}^{\circ}\right) \in \mathscr{D}$. Here and in the following $\|\cdot\|_{k, \infty}$ denotes the infinity norm of the derivatives of the argument up to the order $k$.

Theorem 1. There exist a constant $\varepsilon_{1}>0$, a function $\sigma_{1} \in C^{-}(] 0, \varepsilon_{1}[)$ with $\lim _{\beta \rightarrow 0} \sigma_{1}(\beta)=$ $T\left(g, K_{g}\right)$, and a function $\zeta_{1} \in C^{+}\left(\left[0, T\left(g, K_{g}\right)[)\right.\right.$ such that for all initial data $\left(\stackrel{\circ}{f}, \stackrel{\circ}{K}_{f}\right) \in \mathscr{D}$ with $d_{1}<\varepsilon_{1}$ the corresponding solution $\left(f, K_{f}\right)$ satisfies

$$
T\left(f, K_{f}\right)>\sigma_{1}\left(d_{1}\right)
$$

and

$$
\|f(t)-g(t)\|_{\infty}+\left\|K_{f}(t)-K_{g}(t)\right\|_{\infty} \leqq \zeta_{1}(t) d_{1}, \quad t \in\left[0, \sigma_{1}\left(d_{1}\right)\right] .
$$

In order to prove the global perturbation result we need continuous dependence also with respect to the first derivatives in $x$ and $v$. To this end define

$$
d_{2}:=\|\stackrel{\circ}{f}-\stackrel{g}{g}\|_{1, \infty}+\left\|\stackrel{\circ}{K}_{f}-\stackrel{\circ}{K}_{g}\right\|_{2, \infty}
$$

for $\left(f, K_{f}^{\circ}\right) \in \mathscr{D}$ and consider the following regularity assumption on the solution $\left(g, K_{g}\right)$ :

(R) $\left\{\begin{array}{l}\text { The mapping }\left[0, T\left(g, K_{g}\right)\left[\ni t \mapsto g(t) \in C_{c}^{2}\left(\mathbb{R}^{6}\right)\right.\right. \\ \text { is well defined and continuous with respect to }\|\cdot\|_{2, \infty}\end{array}\right.$.

Theorem 2. Assume that $\left(g, K_{g}\right)$ satisfies condition $(\mathrm{R})$. Then there exist a constant $\left.\left.\varepsilon_{2} \in\right] 0, \varepsilon_{1}\right]$, a function $\sigma_{2} \in C^{-}(] 0, \varepsilon_{2}[)$ with $\lim _{\beta \rightarrow 0} \sigma_{2}(\beta)=T\left(g, K_{g}\right)$, and a function $\zeta_{2} \in C^{+}\left(\left[0, T\left(g, K_{g}\right)[)\right.\right.$ such that for all initial data $\left(\stackrel{\circ}{f, \kappa_{f}}\right) \in \mathscr{D}$ with $d_{2}<\varepsilon_{2}$ the 
corresponding solution $\left(f, K_{f}\right)$ satisfies

$$
T\left(f, K_{f}\right)>\sigma_{1}\left(d_{1}\right) \geqq \sigma_{2}\left(d_{2}\right)
$$

and

$$
\|f(t)-g(t)\|_{1, \infty}+\left\|K_{f}(t)-K_{g}(t)\right\|_{1, \infty} \leqq \zeta_{2}(t) d_{2}, \quad t \in\left[0, \sigma_{2}\left(d_{2}\right)\right] .
$$

It follows from [16] that condition (R) is satisfied if the initial data $\left(\stackrel{\circ}{g}, K_{g}\right)$ are smooth enough. Note that, if the unperturbed solution $\left(g, K_{g}\right)$ is global, the perturbed solution $\left(f, K_{f}\right)$ exists for arbitrarily long times by the above theorems whenever $d_{1}$ or $d_{2}$ are small enough. However, these theorems do not imply that the perturbed solution is global, too. The perturbation of global solutions is investigated under the assumption that the field $K_{g}$ satisfies the following decay condition:

$$
\text { (D) }\left\{\begin{array}{l}
T\left(g, K_{g}\right)=\infty, \text { and there are constants } K_{1} \geqq 0 \text { and } \alpha_{1}>1 / 2, \alpha_{2} \geqq 0 \\
\text { with } \alpha_{1}+\alpha_{2}>1 \text { such that } \\
\left|K_{g}(t, x)\right| \leqq K_{1}(1+t)^{-\alpha_{1}}\left(1+R_{0}+t-|x|\right)^{-\alpha_{2}} \\
\left|\partial_{x} K_{g}(t, x)\right| \leqq K_{1}(1+t)^{-\alpha_{1}}\left(1+R_{0}+t-|x|\right)^{-\alpha_{2}-1} \\
\text { for } t \geqq 0 \text { and }|x| \leqq R_{0}+t .
\end{array}\right.
$$

The following theorem is the main result of the present paper.

Theorem 3. Assume that $\left(g, K_{q}\right)$ satisfies conditions $(\mathrm{R})$ and $(\mathrm{D})$. Then there exist constants $\varepsilon_{3}>0$ and $C>0$ such that for all initial data $\left(f, \kappa_{f}\right) \in \mathscr{D}$ with $d_{2}<\varepsilon_{3}$ the corresponding solution $\left(f, K_{f}\right)$ is global and satisfies

$$
\begin{aligned}
\left|K_{f}(t, x)\right| & \leqq C\left(1+R_{0}+t+|x|\right)^{-1}\left(1+R_{0}+t-|x|\right)^{-1}, \\
\left|\partial_{x} K_{f}(t, x)\right| & \leqq C\left(1+R_{0}+t+|x|\right)^{-1}\left(1+R_{0}+t-|x|\right)^{-7 / 4}
\end{aligned}
$$

for $t \geqq 0$ and $|x| \leqq R_{0}+t$.

Note that the perturbed, global solution $\left(f, K_{f}\right)$ obtained in Theorem 3 satisfies condition (D) with $\alpha_{1}=1$ and $\alpha_{2}=3 / 4$, which may be a stronger estimate than the initial assumption on the unperturbed solution $\left(g, K_{g}\right)$. Horst [10] suggested the estimate

$$
\left\|K_{g}(t)\right\|_{\infty} \leqq p(t), \quad\left\|\partial_{x} K_{g}(t)\right\|_{\infty} \leqq q(t), \quad t \geqq 0
$$

with

$$
\int_{0}^{\infty}(t q(t)+p(t)) d t<\infty
$$

instead of condition (D). While this might be sufficient for global existence of the perturbed solution, the perturbed solution will in general not exhibit the same sort of decay, as may be seen by perturbing off the trivial solution $g=K_{g}=0$ with $\stackrel{\circ}{f}=0$ and observing that a solution of the homogeneous Maxwell system in general decays only like $t^{-1}$ with respect to the infinity norm on $\mathbb{R}^{3}$. It is the key idea of the proof of Theorem 3 that the term $\left(1+R_{0}+t-|x|\right)^{-\alpha_{2}}$ introduces an additional decay of the fields, but only well inside the light cone; that is, for $|x| \leqq R_{0}+C t$ with $0<C<1$. For these reasons condition (D) seems to be more natural than Horst's suggestion. 
Having proved Theorem 3 we will also establish a global estimate for the deviation of $\left(f, K_{f}\right)$ from $\left(g, K_{g}\right)$ at the end of Sect. 5 .

Finally, it remains to be seen that there exist nontrivial solutions $\left(g, K_{g}\right)$ satisfying conditions (R) and (D). As an example consider spherically symmetric solutions. For $(x, v) \in \mathbb{R}^{6}$ with $x \neq 0$ define

$$
r:=|x|, \quad w:=\frac{x \cdot v}{|x|}, \quad F:=x^{2} v^{2}-(x \cdot v)^{2}=|x \times v|^{2}
$$

and call $\stackrel{\circ}{g}$ spherically symmetric if

$$
\stackrel{g}{g}(x, v)=\stackrel{g}{g}(r, w, F) \text { for } \quad x \neq 0 .
$$

If all particles have charges of the same sign, the forces are repulsive, the plasma disperses and the fields decay. In the other case this may be achieved by assuming that initially all particles move outward fast enough to escape to infinity:

$$
\text { (E) }\left\{\begin{array}{l}
\text { There is a constant } \delta>0 \text { such that } w>\delta+\frac{\left|e_{\alpha}\right| M}{\delta r} \sqrt{m_{\alpha}^{2}+\frac{F}{r^{2}}+\delta^{2}} \\
\text { for }(x, v) \in \operatorname{supp} \stackrel{g}{\alpha}_{\alpha} \text { with } x \neq 0,1 \leqq \alpha \leqq N,
\end{array}\right.
$$

where

$$
M:=\sum_{\alpha=1}^{N}\left|e_{\alpha}\right| \iint \stackrel{\circ}{g}_{\alpha}(x, v) d v d x .
$$

Theorem 4. Assume that $0 \leqq g \in C_{c}^{2}\left(\mathbb{R}^{6}\right)$ is spherically symmetric and satisfies condition (E) if there are particles with charges of different signs. Define

$$
\stackrel{\circ}{E}_{g}(x):=\int \frac{x-y}{|x-y|^{3}} \circ_{g}(y) d y, \quad \stackrel{\circ}{B}_{g}:=0
$$

and choose $R_{0}>0, U_{0}>0$, and $K_{0}>0$ such that $\left(\stackrel{\circ}{g}, K_{g}\right) \in \mathscr{D}\left(R_{0}, U_{0}, K_{0}\right)$. Then there exist constants $\varepsilon>0$ and $C>0$ such that for all initial data $\left(f, K_{f}\right) \in \mathscr{D}$ with $d_{2}<\varepsilon$ the corresponding solution $\left(f, K_{f}\right)$ is global and satisfies

$$
\begin{aligned}
\left|K_{f}(t, x)\right| & \leqq C\left(1+R_{0}+t+|x|\right)^{-1}\left(1+R_{0}+t-|x|\right)^{-1} \\
\left|\partial_{x} K_{f}(t, x)\right| & \leqq C\left(1+R_{0}+t+|x|\right)^{-1}\left(1+R_{0}+t-|x|\right)^{-7 / 4}
\end{aligned}
$$

for $t \geqq 0$ and $|x| \leqq R_{0}+t$.

This result is analogous to the one obtained in [14] for VP and extends the class of globally solvable initial data for RVM to not necessarily small or nearly neutral data. In order to prove Theorem 4, conditions (R) and (D) have to be verified. Since in the spherically symmetric case RVM reduces to RVP, this belongs to the investigation of RVP rather than RVM. Thus, the proofs are not included here, and the reader is referred to [10] and [12].

Remark. Besides greater generality our reason for considering $N$ different particle species lies in the fact that it may well make a difference whether there are particles with charges of different signs or not when checking condition (D), cf. Theorem 4. However, in the proofs of the other theorems it only makes the notation cumbersome to assume more than one particle species, but poses no additional 
difficulties. Thus, from now on we assume $N=1, m_{1}=e_{1}=1$ and drop the subscript in $\hat{v}_{1}, f_{1}$ etc.

\section{Preliminary Results on RVM}

The following lemma is a reformulation of results due to Glassey and Strauss and an immediate consequence of [6], Proposition 8.

Lemma 3.1. Given $\left(\stackrel{\circ}{f} \stackrel{\circ}{K}_{f}\right) \in \mathscr{D}$ there exists a unique, classical solution $\left(f, K_{f}\right)$ of RVM with initial data $\left(\stackrel{\circ}{f}, K_{f}^{\circ}\right)$ on a maximal interval of existence $\left[0, T\left(f, K_{f}\right)[\right.$. If

$$
\sup \left\{|v| \mid(x, v) \in \operatorname{supp} f(t), 0 \leqq t<T\left(f, K_{f}\right)\right\}<\infty
$$

then the solution is global; that is, $T\left(f, K_{f}\right)=\infty$.

Next we recall some well known properties of the characteristics of RVM.

Lemma 3.2. The characteristic system

$$
\begin{aligned}
\dot{x} & =\hat{v}, \\
\dot{v} & =E_{f}(t, x)+\hat{v} \times B_{f}(t, x)
\end{aligned}
$$

has a unique solution $\left(X_{f}(\cdot, t, x, v), V_{f}(\cdot, t, x, v)\right)$ on the interval $\left[0, T\left(f, K_{f}\right)[\right.$ with

$$
X_{f}(t, t, x, v)=x, \quad V_{f}(t, t, x, v)=v
$$

where $t \in\left[0, T\left(f, K_{f}\right)\left[\right.\right.$ and $(x, v) \in \mathbb{R}^{6}$. For $s, t \in\left[0, T\left(f, K_{f}\right)[\right.$ the mapping

$$
\mathbb{R}^{6} \ni(x, v) \mapsto\left(X_{f}(s, t, x, v), V_{f}(s, t, x, v)\right) \in \mathbb{R}^{6}
$$

is a measure preserving $C^{1}$-diffeomorphism. Furthermore,

$$
\frac{d}{d s} f\left(s, X_{f}(s, t, x, v), V_{f}(s, t, x, v)\right)=0, \quad s, t \in\left[0, T\left(f, K_{f}\right)\left[, \quad(x, v) \in \mathbb{R}^{6},\right.\right.
$$

and supp $f(t) \subset B_{R_{0}+t}(0) \times \mathbb{R}^{3}$ is compact for $t \in\left[0, T\left(f, K_{f}\right)[\right.$.

The following integral representation of the electromagnetic fields, due to Glassey and Strauss, is a key ingredient in our arguments.

Lemma 3.3. There exist functions

$$
k_{T}, k_{S} \in C\left(\left\{\omega \in \mathbb{R}^{3}|| \omega \mid=1\right\} \times \mathbb{R}^{3}\right)
$$

with

$$
\left|k_{T}(\omega, v)\right|,\left|k_{S}(\omega, v)\right| \leqq C \sqrt{1+v^{2}}, \quad|\omega|=1, \quad v \in \mathbb{R}^{3},
$$

such that for each solution $\left(f, K_{f}\right)$ with initial data $\left(\stackrel{\circ}{f}, \stackrel{\circ}{K}_{f}\right) \in \mathscr{D}$ the following representation holds:

$$
E_{f}=E_{f, D}+E_{f, T}+E_{f, S}
$$

where

$$
E_{f, D}(t, x):=\frac{1}{4 \pi t} \int_{|x-y|=t} \operatorname{curl} \stackrel{\circ}{B}_{f}(y) d S_{y}
$$




$$
\begin{gathered}
+\frac{1}{4 \pi t^{2}} \int_{|x-y|=t}\left(\stackrel{\circ}{f}_{f}(y)+\partial_{x} \stackrel{\circ}{E}_{f}(y) \cdot(y-x)\right) d S_{y} \\
-\frac{1}{t} \int_{|x-y|=t} \int \frac{\omega+\hat{v}}{1+\omega \cdot \hat{v}} \stackrel{\circ}{f}(y, v) d v d S_{y}, \\
E_{f, T}(t, x):=\int_{|x-y| \leqq t} \int k_{T}(\omega, v) f(t-|x-y|, y, v) d v \frac{d y}{|x-y|^{2}}, \\
E_{f, S}(t, x):=\int_{|x-y| \leqq t} \int k_{S}(\omega, v)\left(f L_{f}\right)(t-|x-y|, y, v) d v \frac{d y}{|x-y|},
\end{gathered}
$$

and

$$
\omega:=\frac{y-x}{|y-x|}, \quad L_{f}(t, x, v):=E_{f}(t, x)+\hat{v} \times B_{f}(t, x) .
$$

The representation for $B_{f}$ is completely analogous with kernels having the same properties as the ones for $E_{f}$.

Proof. These formulas are given in [6], Theorem 3 with

$$
k_{T}(\omega, v):=-\frac{1-\hat{v}^{2}}{(1+\omega \cdot \hat{v})^{2}}(\omega+\hat{v}), \quad k_{S}(\omega, v):=-\partial_{v}\left(\frac{\omega+\hat{v}}{1+\omega \cdot \hat{v}}\right) .
$$

For the estimates of the kernels cf. [7], p. $48 \mathrm{f}$, the explicit form of the data term which is not given in [6] may be verified by going through the proof.

We will also need a representation for the derivatives of the fields, which is again due to Glassey and Strauss, cf. [6], Theorem 4.

Lemma 3.4. There exist functions

$$
k_{T T}, k_{T S}, k_{S S} \in C\left(\{|\omega|=1\} \times \mathbb{R}^{3}\right)
$$

with

$$
\begin{aligned}
& \partial_{v} k_{S S} \in C\left(\{|\omega|=1\} \times \mathbb{R}^{3}\right), \\
& \left|k_{T T}(\omega, v)\right|,\left|k_{T S}(\omega, v)\right|,\left|k_{S S}(\omega, v)\right|,\left|\partial_{v} k_{S S}(\omega, v)\right| \leqq C(1+\omega \cdot \hat{v})^{-4}, \quad|\omega|=1, \quad v \in \mathbb{R}^{3}
\end{aligned}
$$

and

$$
\int_{|\omega|=1} k_{T T}(\omega, v) d S_{\omega}=0, \quad v \in \mathbb{R}^{3},
$$

such that for each solution $\left(f, K_{f}\right)$ with initial data $\left(\stackrel{\circ}{f}, \stackrel{\circ}{K}_{f}\right) \in \mathscr{D}$ and $k=1,2,3$, the following representation holds:

$$
\partial_{x_{k}} E_{f}=E_{f, D D}+E_{f, T T}+E_{f, T S}+E_{f, S S}+E_{f, R},
$$

where

$$
\begin{aligned}
& E_{f, D D}(t, x):=\partial_{x_{k}} E_{f, D}(t, x) \\
& +\frac{1}{t^{2}} \int_{|x-y|=t} \int \frac{\omega_{k}(\omega+\hat{v})}{\left(1+v^{2}\right)(1+\omega \cdot \hat{v})^{3}} \stackrel{\circ}{f}(y, v) d v d S_{y} \\
& -\frac{1}{t} \int_{|x-y|=t} \int \frac{\omega_{k}}{1+\omega \cdot \hat{v}} \partial_{v}\left(\frac{\omega+\hat{v}}{1+\omega \cdot \hat{v}}\right)\left(\stackrel{\circ}{f} \stackrel{\circ}{f}_{f}\right)(y, v) d v d S_{y},
\end{aligned}
$$




$$
\begin{aligned}
& E_{f, T T}(t, x):=\oint_{|x-y| \leqq t} \int k_{T T}(\omega, v) f(t-|x-y|, y, v) d v \frac{d y}{|x-y|^{3}}, \\
& E_{f, T S}(t, x):=\int_{|x-y| \leqq t} \int k_{T S}(\omega, v)\left(f L_{f}\right)(t-|x-y|, y, v) d v \frac{d y}{|x-y|^{2}}, \\
& E_{f, S S}(t, x):=\int_{|x-y| \leqq t} \int k_{S S}(\omega, v) S\left(f L_{f}\right)(t-|x-y|, y, v) d v \frac{d y}{|x-y|} \\
& E_{f, R}(t, x):=\int \frac{1}{1+v^{2}} \int_{|\omega|=1} \frac{\omega+\hat{v}}{(1+\omega \cdot \hat{v})^{3}} \omega_{k} d S_{\omega} f(t, x, v) d v .
\end{aligned}
$$

Here

$$
\oint_{|x-y| \leqq t}:=\lim _{\varepsilon \rightarrow 0} \int_{\varepsilon \leqq|x-y| \leqq t}
$$

denotes the Cauchy principal value of the integral and

$$
S:=\partial_{t}+\hat{v} \cdot \partial_{x} .
$$

The derivatives of $B_{f}$ can be represented in a completely analogous way with kernels having the same properties as the ones for $E_{f}$.

Corollary 3.5. For a maximal solution $\left(f, K_{f}\right)$ of $\mathrm{RVM}$ with initial data from $\mathscr{D}$ the mappings

and

$$
\left[0, T\left(f, K_{f}\right)\left[\ni t \mapsto f(t) \in C_{c}^{1}\left(\mathbb{R}^{6}, \mathbb{R}^{N}\right),\right.\right.
$$

$$
\left[0, T\left(f, K_{f}\right)\left[\ni t \mapsto K_{f}(t) \in C_{b}^{1}\left(\mathbb{R}^{3}, \mathbb{R}^{6}\right)\right.\right.
$$

are well defined and continuous with respect to the norm $\|\cdot\|_{1, \infty}$.

\section{Local Results}

In order to prove Theorem 1, we have to introduce a few definitions and collect some auxiliary lemmas first. Throughout this section assume that $\left(\stackrel{\circ}{f}, K_{f}\right) \in \mathscr{D}$ with $d_{1}<1$. Any constant or function $C \in C^{+}\left(\left[0, T\left(g, K_{g}\right)[)\right.\right.$ may depend on the unperturbed solution $\left(g, K_{g}\right)$, but not on the perturbed solution $\left(f, K_{f}\right)$, and may change from line to line. Define

$$
\begin{aligned}
T_{0}\left(f, K_{f}\right):=\sup \{t & t \in\left[0, \min \left\{T\left(f, K_{f}\right), T\left(g, K_{g}\right)\right\}[\mid\right. \\
& \left.\left\|K_{f}(s)-K_{g}(s)\right\|_{\infty} \leqq(1+s)^{-2}, s \in[0, t]\right\}
\end{aligned}
$$

and

$$
U(t):=U_{0}+1+\int_{0}^{t}\left\|K_{g}(s)\right\|_{\infty} d s, \quad t \in\left[0, T\left(g, K_{g}\right)[.\right.
$$

Note that Lemma 3.5 and the assumption $d_{1}<1$ imply $T_{0}\left(f, K_{f}\right)>0$ and that $U \in C^{+}\left(\left[0, T\left(g, K_{g}\right)[)\right.\right.$. On the interval $\left[0, T_{0}\left(f, K_{f}\right)[\right.$ we may now estimate the momenta as follows:

Lemma 4.1. For all initial data $\left(\stackrel{\circ}{f}, \stackrel{\circ}{K}_{f}\right) \in \mathscr{D}$ and $t \in\left[0, T_{0}\left(f, K_{f}\right)[\right.$

$$
\sup \{|v| \mid(x, v) \in \operatorname{supp} f(t)\} \leqq U(t) .
$$


Proof. The proof is immediate, since

$$
\operatorname{supp} f(t)=\left\{\left(X_{f}(t, 0, x, v), V_{f}(t, 0, x, v)\right) \mid(x, v) \in \operatorname{supp} f\right\}
$$

and

$$
\left|\dot{V}_{f}(t, 0, x, v)\right| \leqq\left\|K_{f}(t)\right\|_{\infty} \leqq\left\|K_{g}(t)\right\|_{\infty}+(1+t)^{-2}, \quad t \in\left[0, T_{0}\left(f, K_{f}\right)[.\right.
$$

Using Lemma 3.3 and Lemma 4.1 we obtain an estimate for the difference of the fields on the interval $\left[0, T_{0}\left(f, K_{f}\right)[\right.$ :

Lemma 4.2. There exists a function $C \in C^{+}\left(\left[0, T\left(g, K_{g}\right)[]\right.\right.$ such that for all initial data $\left(\stackrel{\circ}{f}, K_{f}\right) \in \mathscr{D}$ with $d_{1}<1$ and $t \in\left[0, T_{0}\left(f, K_{f}\right)[\right.$ the following estimate holds:

$$
\begin{aligned}
\left\|K_{f}(t)-K_{g}(t)\right\|_{\infty} \leqq & C(t) d_{1}+C(t) U(t)^{4} \\
& \cdot\left(\sup _{0 \leqq \tau \leqq t}\|f(\tau)-g(\tau)\|_{\infty}+\int_{0}^{t}\left\|K_{f}(\tau)-K_{g}(\tau)\right\|_{\infty} d \tau\right) .
\end{aligned}
$$

Remark. The reason for making the dependence on $U$ explicit in the above estimate will become apparent in the proof of Theorem 1.

Proof. Consider the integral representation for $E_{f}$ and $E_{g}$ given in Lemma 3.3. Obviously

$$
\left\|E_{f, D}(t)-E_{g, D}(t)\right\|_{\infty} \leqq C(t) d_{1} .
$$

By Lemma 4.1, it suffices to integrate over $v$ with $|v| \leqq U(t-|x-y|) \leqq U(t)$ in the formulas for $E_{f, T}, E_{f, s}, E_{g, T}$, and $E_{g, s}$. Thus, we may estimate

$$
\left|k_{T}(\omega, v)\right|,\left|k_{S}(\omega, v)\right| \leqq C U(t)
$$

to obtain

$$
\left\|E_{f, T}(t)-E_{g, T}(t)\right\|_{\infty} \leqq C(t) U(t)^{4} \sup _{0 \leqq \tau \leqq t}\|f(\tau)-g(\tau)\|_{\infty}
$$

and

$$
\left|E_{f, S}(t, x)-E_{g, S}(t, x)\right| \leqq C U(t) \int_{|x-y| \leqq t|v| \leqq U(t)}\left|f L_{f}-g L_{g}\right|(t-|x-y|, y, v) d v \frac{d y}{|x-y|} .
$$

Putting

$$
\left|f L_{f}-g L_{g}\right| \leqq|f|\left|K_{f}-K_{g}\right|+\left|K_{g}\right||f-g|
$$

and

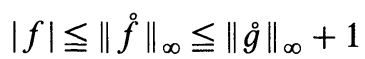

into the last estimate yields

$$
\left\|E_{f, S}(t)-E_{g, s}(t)\right\|_{\infty} \leqq C(t) U(t)^{4}\left(\sup _{0 \leqq \tau \leqq t}\|f(\tau)-g(\tau)\|_{\infty}+\int_{0}^{t}\left\|K_{f}(\tau)-K_{g}(\tau)\right\|_{\infty} d \tau\right) .
$$

Analogous estimates for the difference $B_{f}-B_{g}$ complete the proof.

Proof of Theorem 1. Let $\left(\stackrel{\circ}{\tilde{K}}, \mathscr{K}_{f}\right) \in \mathscr{D}$ satisfy $d_{1}<1$. For $0 \leqq s \leqq t<\min \left\{T\left(f, K_{f}\right)\right.$, 
$\left.T\left(g, K_{g}\right)\right\}$ and $(x, v) \in \mathbb{R}^{6}$ we have

$$
\begin{aligned}
& \frac{d}{d s}\left((f-g)\left(s, X_{f}(s, t, x, v), V_{f}(s, t, x, v)\right)\right) \\
& \quad=-\left(\partial_{v} g \cdot\left(L_{f}-L_{g}\right)\right)\left(s, X_{f}(s, t, x, v), V_{f}(s, t, x, v)\right) .
\end{aligned}
$$

Integrating this equation from 0 to $t$ and estimating, we obtain

$$
\begin{aligned}
(f-g)(t, x, v)= & (\stackrel{\circ}{f}-g)\left(X_{f}(0, t, x, v), V_{f}(0, t, x, v)\right) \\
& -\int_{0}^{t}\left(\partial_{v} g \cdot\left(L_{f}-L_{g}\right)\right)\left(s, X_{f}(s, t, x, v), V_{f}(s, t, x, v)\right) d s
\end{aligned}
$$

and

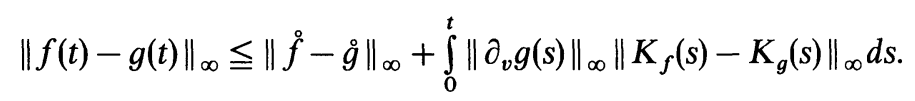

For $t \in\left[0, T_{0}\left(f, K_{f}\right)[\right.$ Lemma 4.2 and the estimate (4.2) imply

$$
\left\|K_{f}(t)-K_{g}(t)\right\|_{\infty} \leqq C(t) U(t)^{4}\left(d_{1}+\int_{0}^{t}\left\|K_{f}(\tau)-K_{g}(\tau)\right\|_{\infty} d \tau\right) .
$$

Since the functions $C$ and $U$ are increasing, we have for $0 \leqq t \leqq t^{\prime}<T_{0}\left(f, K_{f}\right)$,

$$
\left\|K_{f}(t)-K_{g}(t)\right\|_{\infty} \leqq C\left(t^{\prime}\right) U\left(t^{\prime}\right)^{4}\left(d_{1}+\int_{0}^{t}\left\|K_{f}(\tau)-K_{g}(\tau)\right\|_{\infty} d \tau\right) .
$$

Now apply Gronwall's lemma, set $t^{\prime}=t$, and obtain

$$
\left\|K_{f}(t)-K_{g}(t)\right\|_{\infty} \leqq(1+t)^{-2} \xi_{1}(t) d_{1}, \quad t \in\left[0, T_{0}\left(f, K_{f}\right)[\right.
$$

where $\xi_{1} \in C^{+}\left(\left[0, T\left(g, K_{g}\right)[)\right.\right.$ is defined by

$$
\xi_{1}(t):=(1+t)^{2} C(t) U(t)^{4} \exp \left(t C(t) U(t)^{4}\right) .
$$

Obviously $\xi_{1}$ is strictly increasing, and $\lim _{t \rightarrow T\left(g, K_{g}\right)} \xi_{1}(t)=\infty$. If $T\left(g, K_{g}\right)=\infty$, this follows from $\lim _{t \rightarrow \infty}(1+t)^{2}=\infty$, if $T\left(g, K_{g}\right) \stackrel{t \rightarrow T\left(g, K_{g}\right)}{<\infty}$, then Lemma 3.1, applied to the solution $\left(g, K_{g}\right)$, implies $\lim _{t \rightarrow T\left(g, K_{g}\right)} U(t)=\infty$. Define

$$
\varepsilon_{1}:=\min \left\{1, \frac{1}{2 \xi_{1}(0)}\right\}, \quad \sigma_{1}(\beta):=\left(\xi_{1}\right)^{-1}\left(\frac{1}{2 \beta}\right) \text { for } 0<\beta<\varepsilon_{1},
$$

to obtain

$$
\sigma_{1} \in C^{-}(] 0, \varepsilon_{1}[), \quad \lim _{\beta \rightarrow 0} \sigma_{1}(\beta)=T\left(g, K_{g}\right) .
$$

If $d_{1}<\varepsilon_{1}$ then $\sigma_{1}\left(d_{1}\right)>0$, and on the interval $\left[0, \min \left\{\sigma_{1}\left(d_{1}\right), T_{0}\left(f, K_{f}\right)\right\}[\right.$ the estimate (4.3) implies

$$
\left\|K_{f}(t)-K_{g}(t)\right\|_{\infty}<\frac{1}{2}(1+t)^{-2}
$$

Assume that $T\left(f, K_{f}\right) \leqq \sigma_{1}\left(d_{1}\right)$. This entails

$$
T_{0}\left(f, K_{f}\right)=\min \left\{T\left(g, K_{g}\right), T\left(f, K_{f}\right)\right\}=T\left(f, K_{f}\right)
$$


so we may apply Lemma 4.1 on the whole interval $\left[0, T\left(f, K_{f}\right)[\right.$, obtaining

$$
\sup \{|v| \mid(x, v) \in \sup f(t)\} \leqq U(t) \leqq U\left(T\left(f, K_{f}\right)\right)<\infty
$$

in contradiction to Lemma 3.1. Thus we have shown that $T\left(f, K_{f}\right)>\sigma_{1}\left(d_{1}\right)$, by (4.4) this yields $T_{0}\left(f, K_{f}\right)>\sigma_{1}\left(d_{1}\right)$, and by (4.3) we finally get

$$
\left\|K_{f}(t)-K_{g}(t)\right\|_{\infty} \leqq(1+t)^{-2} \xi_{1}(t) d_{1}, t \in\left[0, \sigma_{1}\left(d_{1}\right)\right] .
$$

Observing (4.2) completes the proof.

In addition to Theorem 1 the above proof also established the following result:

Corollary 4.3. Assume that $\left(\stackrel{\circ}{f}, \stackrel{\circ}{K}_{f}\right) \in \mathscr{D}$ with $d_{1}<\varepsilon_{1}$ and $t \in\left[0, \sigma_{1}\left(d_{1}\right)\right]$. Then

$$
\left\|K_{f}(t)-K_{g}(t)\right\|_{\infty} \leqq(1+t)^{-2}
$$

and

$$
\sup \{|v| \mid(x, v) \in \sup f(t)\} \leqq U(t) .
$$

We now turn to the proof of Theorem 2. The following lemma gives an estimate for the differences of the spatial derivatives of the fields similar to Lemma 4.2.

Lemma 4.4. There exists a function $C \in C^{+}\left(\left[0, T\left(g, K_{g}\right)[)\right.\right.$ such that for all initial data $\left(\stackrel{\circ}{f}, \stackrel{\circ}{K}_{f}\right) \in \mathscr{D}$ with $d_{1}<\varepsilon_{1}$ and $t \in\left[0, \sigma_{1}\left(d_{1}\right)\right]$ the following estimate holds:

$$
\begin{aligned}
\left\|\partial_{x} K_{f}(t)-\partial_{x} K_{g}(t)\right\|_{\infty} \leqq & C(t) U(t)^{4}\left(d_{2}+\sup _{0 \leqq \tau \leqq t}\left\|\partial_{x} f(\tau)-\partial_{x} g(\tau)\right\|_{\infty}\right. \\
& \left.+\int_{0}^{t}\left\|\partial_{x} K_{f}(\tau)-\partial_{x} K_{g}(\tau)\right\|_{\infty} d \tau\right) .
\end{aligned}
$$

Proof. First note that it would be possible, but unnecessarily complicated to use Lemma 3.4 at this point. Instead, we use Lemma 3.3 and differentiate under the integral sign. Since the proof is then similar to the proof of Lemma 4.2 we only treat the difference $\partial_{x} E_{f, s}-\partial_{x} E_{g, s}$. With

$$
\partial_{x} E_{f, S}(t, x)=\int_{|x-y| \leqq t|v| \leqq U(t)} \int_{S}(\omega, v) \partial_{x}\left(f L_{f}\right)(t-|x-y|, y, v) d v \frac{d y}{|x-y|},
$$

the corresponding expression for $\partial_{x} E_{g, S}$ and Lemma 4.1 we obtain the estimate

$$
\begin{aligned}
& \left|\partial_{x} E_{f, S}(t, x)-\partial_{x} E_{g, S}(t, x)\right| \\
& \quad \leqq C U(t) \int_{|x-y| \leqq t|v| \leqq U(t)}\left|\partial_{x}\left(f L_{f}\right)-\partial_{x}\left(g L_{g}\right)\right|(t-|x-y|, y, v) d v \frac{d y}{|x-y|}
\end{aligned}
$$

for $t \in\left[0, \sigma_{1}\left(d_{1}\right)\right]$ and $x \in \mathbb{R}^{3}$. Putting

$$
\begin{aligned}
& \left|\partial_{x}\left(f L_{f}\right)-\partial_{x}\left(g L_{g}\right)\right| \leqq\left|\partial_{x} f-\partial_{x} g\right|\left|K_{f}\right|+\left|\partial_{x} g\right|\left|K_{f}-K_{g}\right| \\
& +|f|\left|\partial_{x} K_{f}-\partial_{x} K_{g}\right|+|f-g|\left|\partial_{x} K_{g}\right|,
\end{aligned}
$$

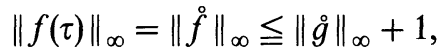

$$
\begin{aligned}
& \left\|K_{f}(\tau)\right\|_{\infty} \leqq\left\|K_{g}(\tau)\right\|_{\infty}+\left\|K_{f}(\tau)-K_{g}(\tau)\right\|_{\infty} \\
& \leqq\left\|K_{g}(\tau)\right\|_{\infty}+\zeta_{1}(\tau) d_{1} \leqq C(\tau)
\end{aligned}
$$


and

$$
\|f(\tau)-g(\tau)\|_{\infty}+\left\|K_{f}(\tau)-K_{g}(\tau)\right\|_{\infty} \leqq \zeta_{1}(\tau) d_{1}, \quad \tau \in\left[0, \sigma_{1}\left(d_{1}\right)\right]
$$

into the estimate for $\partial_{x} E_{f, S}-\partial_{x} E_{g, S}$, we end up with

$$
\begin{aligned}
& \left\|\partial_{x} E_{f, S}(t)-\partial_{x} E_{g, S}(t)\right\|_{\infty} \\
& \quad \leqq C(t) U(t)^{4}\left(d_{1}+\sup _{0 \leqq \tau \leqq t}\left\|\partial_{x} f(\tau)-\partial_{x} g(\tau)\right\|_{\infty}+\int_{0}^{t}\left\|\partial_{x} K_{f}(\tau)-\partial_{x} K_{g}(\tau)\right\|_{\infty} d \tau\right) .
\end{aligned}
$$

The remaining estimates are similar and therefore omitted.

In order to prove Theorem 2 we need to estimate the derivatives of the characteristics of $f$ with respect to $x$ and $v$.

Lemma 4.5. For $\left(\stackrel{\circ}{f} \stackrel{\circ}{K}_{f}\right) \in \mathscr{D}, 0 \leqq s \leqq t<T\left(f, K_{f}\right)$, and $(x, v) \in \mathbb{R}^{6}$ the following estimates hold:

$$
\begin{array}{r}
\left|\partial_{x} X_{f}(s, t, x, v)\right|+\left|\partial_{x} V_{f}(s, t, x, v)\right| \leqq \exp \left(\int_{s}^{t}\left(3+3\left\|B_{f}(\tau)\right\|_{\infty}+\left\|\partial_{x} K_{f}(\tau)\right\|_{\infty}\right) d \tau\right), \\
\left|\partial_{v} X_{f}(s, t, x, v)\right|+\left|\partial_{v} V_{f}(s, t, x, v)\right| \leqq \exp \left(\int_{s}^{t}\left(3+3\left\|B_{f}(\tau)\right\|_{\infty}+\left\|\partial_{x} K_{f}(\tau)\right\|_{\infty}\right) d \tau\right) .
\end{array}
$$

Proof. Differentiating the characteristic system we obtain

$$
\begin{aligned}
\frac{d}{d s} \partial_{x_{k}} X_{f}(s)= & \frac{\partial_{x_{k}} V_{f}(s)}{\sqrt{1+V_{f}^{2}(s)}}-\partial_{x_{k}} V_{f}(s) \cdot V_{f}(s) \frac{V_{f}(s)}{\left(1+V_{f}^{2}(s)\right)^{3 / 2}} \\
\frac{d}{d s} \partial_{x_{k}} V_{f}(s)= & \partial_{x} E_{f}\left(s, X_{f}(s)\right) \cdot \partial_{x_{k}} X_{f}(s)+\frac{V_{f}(s)}{\sqrt{1+V_{f}^{2}(s)}} \times\left(\partial_{x} B_{f}\left(s, X_{f}(s)\right) \cdot \partial_{x_{k}} X_{f}(s)\right) \\
& +\left(\frac{\partial_{x_{k}} V_{f}(s)}{\sqrt{1+V_{f}^{2}(s)}}-\frac{\partial_{x_{k}} V_{f}(s) \cdot V_{f}(s) V_{f}(s)}{\left(1+V_{f}^{2}(s)\right)^{3 / 2}}\right) \times B_{f}\left(s, X_{f}(s)\right) .
\end{aligned}
$$

Now some straightforward estimates and Gronwall's lemma yield the desired result.

Proof of Theorem 2. Assume that the unperturbed solution $\left(g, K_{g}\right)$ satisfies the regularity condition (R) and differentiate equation (4.1) to obtain

$$
\begin{aligned}
\partial_{x_{k}}(f-g)(t, x, v)= & \partial_{x}(\stackrel{\circ}{f}-\stackrel{g}{g})\left(X_{f}(0, t, x, v), V_{f}(0, t, x, v)\right) \cdot \partial_{x_{k}} X_{f}(0, t, x, v) \\
& +\partial_{v}(f-g)\left(X_{f}(0, t, x, v), V_{f}(0, t, x, v)\right) \cdot \partial_{x_{k}} V_{f}(0, t, x, v) \\
& -\int_{0}^{t}\left(\partial_{x}\left(L_{f}-L_{g}\right) \cdot \partial_{x_{k}} X_{f}(s, t, x, v)\right. \\
& \left.+\partial_{x_{k}} \hat{V}_{f}(s, t, x, v) \times\left(B_{f}-B_{g}\right)\right) \cdot \partial_{v} g\left(s, X_{f}(s), V_{f}(s)\right) d s \\
& -\int_{0}^{t}\left(L_{f}-L_{g}\right)\left(\partial_{x} \partial_{v} g \cdot \partial_{x_{k}} X_{f}(s, t, x, v)\right. \\
& \left.+\partial_{v}^{2} g \cdot \partial_{x_{k}} V_{f}(s, t, x, v)\right) d s .
\end{aligned}
$$


For $t \in\left[0, T\left(f, K_{f}\right)[\right.$ define

$$
P(t):=\sup \left\{\left|\partial_{x} X_{f}(s, t, x, v)\right|+\left|\partial_{x} V_{f}(s, t, x, v)\right| \mid 0 \leqq s \leqq t,(x, v) \in \mathbb{R}^{6}\right\} .
$$

Assuming $\left(f, \stackrel{\circ}{K}_{f}\right) \in \mathscr{D}$ with $d_{1}<\varepsilon_{1}$ and $t \in\left[0, \sigma_{1}\left(d_{1}\right)\right]$, Theorem 1, Eq. (4.5) and Lemma 4.4 imply

$$
\left\|\partial_{x} K_{f}(t)-\partial_{x} K_{g}(t)\right\|_{\infty} \leqq C(t) U(t)^{4}(1+P(t))\left(d_{2}+\int_{0}^{t}\left\|\partial_{x} K_{f}(s)-\partial_{x} K_{g}(s)\right\|_{\infty} d s\right) .
$$

Gronwall's lemma now gives the following estimate for $t \in\left[0, \sigma_{1}\left(d_{1}\right)\right]$ :

$$
\left\|\partial_{x} K_{f}(t)-\partial_{x} K_{g}(t)\right\|_{\infty} \leqq C(t) U(t)^{4}(1+P(t)) \exp \left(t C(t) U(t)^{4}(1+P(t))\right) d_{2} .
$$

Thus, the function $P$, which depends on $\left(f, K_{f}\right)$, has to be estimated independently of $\left(f, K_{f}\right)$. By Lemma 4.5 and Theorem 1 ,

$$
\begin{aligned}
P(t) & \leqq \exp \left(\int_{0}^{t}\left(3+3\left\|B_{g}(s)\right\|_{s}+3 \zeta_{1}(s) d_{1}+\left\|\partial_{x} K_{g}(s)\right\|_{\infty}+\left\|\partial_{x} K_{f}(s)-\partial_{x} K_{g}(s)\right\|_{\infty}\right) d s\right) \\
& \leqq \exp \left(\int_{0}^{t}\left(C(s)+\left\|\partial_{x} K_{f}(s)-\partial_{x} K_{g}(s)\right\|_{\infty}\right) d s\right), \quad t \in\left[0, \sigma_{1}\left(d_{1}\right)\right] .
\end{aligned}
$$

Since $d_{2}<\varepsilon_{1} \leqq 1$,

$$
T_{1}\left(f, K_{f}\right):=\sup \left\{t \in\left[0, \sigma_{1}\left(d_{1}\right)\right] \mid\left\|\partial_{x} K_{f}(s)-\partial_{x} K_{g}(s)\right\|_{\infty} \leqq 1,0 \leqq s \leqq t\right\}>0,
$$

and

$$
P(t) \leqq \exp \left(\int_{0}^{t}(C(s)+1) d s\right), \quad t \in\left[0, T_{1}\left(f, K_{f}\right)\right],
$$

where $C \in C^{+}\left(\left[0, T\left(g, K_{g}\right)[)\right.\right.$. Define

$$
\bar{P}(t):=\exp \left(\int_{0}^{t}(C(s)+1) d s\right), \quad t \in\left[0, T\left(g, K_{g}\right)[,\right.
$$

and

$$
\xi_{2}(t):=C(t) U(t)^{4}(1+\bar{P}(t)) \exp \left(t C(t) U(t)^{4}(1+\bar{P}(t))\right),
$$

and observe that the function $\xi_{2} \in C^{+}\left(\left[0, T\left(g, K_{g}\right)[)\right.\right.$ is strictly increasing with $\lim _{\rightarrow T\left(g, K_{g}\right)} \xi_{2}(t)=\infty$. For $t \in\left[0, T_{1}\left(f, K_{f}\right)\right]$ the estimate (4.6) implies

Now

$$
\left\|\partial_{x} K_{f}(t)-\partial_{x} K_{g}(t)\right\|_{\infty} \leqq \xi_{2}(t) d_{2} .
$$

$$
\varepsilon_{2}:=\min \left\{\varepsilon_{1}, \frac{1}{\xi_{2}(0)}\right\}, \quad \sigma_{2}(\beta):=\min \left\{\sigma_{1}(\beta),\left(\xi_{2}\right)^{-1}(1 / \beta)\right\}, \quad 0<\beta<\varepsilon_{2}
$$

yields

$$
\sigma_{2} \in C^{-}(] 0, \varepsilon_{2}[), \quad \lim _{\beta \rightarrow 0} \sigma_{2}(\beta)=T\left(g, K_{g}\right) .
$$

Assume that $T_{1}\left(f, K_{f}\right)<\sigma_{2}\left(d_{2}\right)$ for $d_{2}<\varepsilon_{2}$. Then the estimate (4.7) implies

$$
\left\|\partial_{x} K_{f}\left(T_{1}\left(f, K_{f}\right)\right)-\partial_{x} K_{g}\left(T_{1}\left(f, K_{f}\right)\right)\right\|_{\infty}<\xi_{2}\left(\sigma_{2}\left(d_{2}\right)\right) d_{2}=1,
$$


contradicting the definition on $T_{1}\left(f, K_{f}\right)$. Hence

$$
\sigma_{2}\left(d_{2}\right) \leqq T_{1}\left(f, K_{f}\right) \leqq \sigma_{1}\left(d_{1}\right)<T\left(f, K_{f}\right) .
$$

For $t \in\left[0, \sigma_{2}\left(d_{2}\right)\right]$ we have established the estimate

$$
\left\|\partial_{x} K_{f}(t)-\partial_{x} K_{g}(t)\right\|_{\infty} \leqq \xi_{2}(t) d_{2},
$$

putting this into (4.5) results in a corresponding estimate for $\left\|\partial_{x} f(t)-\partial_{x} g(t)\right\|_{\infty}$. Since $\sigma_{2}\left(d_{2}\right) \leqq \sigma_{1}\left(d_{1}\right)$, all the estimates from Theorem 1 remain valid on the interval $\left[0, \sigma_{2}\left(d_{2}\right)\right]$, so only the difference $\partial_{v} f(t)-\partial_{v} g(t)$ remains to be estimated. To this end note that on the interval $\left[0, \sigma_{2}\left(d_{2}\right)\right]$ Lemma 4.5 implies

$$
Q(t):=\sup \left\{\left|\partial_{v} X_{f}(s, t, x, v)\right|+\left|\partial_{v} V_{f}(s, t, x, v)\right| \mid 0 \leqq s \leqq t,(x, v) \in \mathbb{R}^{6}\right\} \leqq \bar{P}(t) .
$$

This completes the proof, since the remaining estimate now follows from an equation for $\partial_{v_{k}}(f-g)(t, x, v)$ analogous to (4.5) and the already established estimates for $\left\|K_{f}(t)-K_{g}(t)\right\|_{1, \infty}$ and $\|f(t)-g(t)\|_{\infty}$.

\section{Global Results}

5.1. Global Existence of the Perturbed Solution. Let us briefly describe the idea of the proof of Theorem 3. The decay condition (D) implies the existence of a time $T_{1}>0$ such that for larger times the field $K_{g}(t)$ and its derivative $\partial_{x} K_{g}(t)$ are so small that the solution $\left(g, K_{g}\right)$ behaves almost like a free streaming. Theorem 2 implies that for $d_{2}$ small enough the perturbed solution $\left(f, K_{f}\right)$ also behaves almost like a free streaming, at least on some interval $I$, which starts at $T_{1}$. On this interval the volume of the support of the function $f(t, x, \cdot)$ decays like $t^{-3}$ and the momenta remain bounded. This implies estimates for the field and its derivative such that the interval $I$ may be extended to infinity and the proof is complete.

For the rest of this section let $\left(g, K_{g}\right)$ be a solution satisfying the conditions (R) and (D). Constants such as $C, c_{1}, C_{1}, c_{2}, C_{2}$ may depend on $\left(g, K_{g}\right)$, but not on the perturbed solution $\left(f, K_{f}\right)$; dependence on $\left(f, K_{f}\right)$ is always explicitly noted.

A first consequence of condition (D) is the following estimate for the momenta of the perturbed solution.

Lemma 5.1. There is a constant $c_{1}>0$ such that

$$
\sup \{|v| \mid(x, v) \in \operatorname{supp} f(t)\} \leqq c_{1}
$$

for all initial data $\left(\stackrel{\circ}{f}, \stackrel{\circ}{K}_{f}\right) \in \mathscr{D}$ with $d_{2}<\varepsilon_{2}$ and $t \in\left[0, \sigma_{2}\left(d_{2}\right)\right]$.

Proof. Take $t \in\left[0, \sigma\left(d_{2}\right)\right]$. Because of $\sigma_{2}\left(d_{2}\right) \leqq \sigma_{1}\left(d_{1}\right)$ and Corollary 4.3 we have

$$
\left\|K_{f}(t)-K_{g}(t)\right\|_{\infty} \leqq(1+t)^{-2} \text {. }
$$

Together with condition (D) this implies

$$
\left|K_{f}(t, x)\right| \leqq K_{1}(1+t)^{-\alpha_{1}}\left(1+R_{0}+t-|x|\right)^{-\alpha_{2}}+(1+t)^{-2}, \quad|x| \leqq R_{0}+t .
$$

Without loss of generality we may assume $\alpha_{2} \leqq 1 / 2$. Now observe that

$$
\operatorname{supp} f(t)=\left\{\left(X_{f}(t, 0, x, v), V_{f}(t, 0, x, v)\right) \mid(x, v) \in \operatorname{supp} \stackrel{\circ}{f}\right\}
$$


and define

$$
u(t):=\sup \left\{\left|V_{f}(s, 0, x, v)\right| \mid 0 \leqq s \leqq t\right\}, \quad \hat{u}(t):=\frac{u(t)}{\sqrt{1+u(t)^{2}}}
$$

for $(x, v) \in \operatorname{supp} f$. The characteristic system implies

$$
\left|\dot{X}_{f}(s, 0, x, v)\right|=\left|\hat{V}_{f}(s, 0, x, v)\right| \leqq \hat{u}(s),
$$

whence

$$
\left|X_{f}(s)\right| \leqq R_{0}+s \hat{u}(s)
$$

and

$$
\begin{aligned}
\left|\dot{V}_{f}(s, 0, x, v)\right| & \leqq K_{1}(1+s)^{-\alpha_{1}}\left(1+R_{0}+s-\left|X_{f}(s)\right|\right)^{-\alpha_{2}}+(1+s)^{-2} \\
& \leqq K_{1}(1+s)^{-\alpha_{1}}(1+s(1-\hat{u}(s)))^{-\alpha_{2}}+(1+s)^{-2}
\end{aligned}
$$

Integrating this inequality we obtain

$$
u(t) \leqq 1+U_{0}+K_{1} \int_{0}^{t}(1+s)^{-\alpha_{1}}(1+s(1-\hat{u}(s)))^{-\alpha_{2}} d s .
$$

A short computation shows that

$$
1 \geqq 1-\hat{u} \geqq \frac{1}{2} \frac{1}{1+u^{2}},
$$

and hence

$$
u(t) \leqq 1+U_{0}+2^{\alpha_{2}} K_{1} \int_{0}^{t}(1+s)^{-\alpha}\left(1+u(s)^{2}\right)^{\alpha_{2}} d s
$$

where $\alpha:=\alpha_{1}+\alpha_{2}$. Let $z:\left[0, t_{\max }\left[\rightarrow \mathbb{R}^{+}\right.\right.$be the maximal solution of

$$
\dot{z}(t)=2^{\alpha_{2}} K_{1}(1+t)^{-\alpha}\left(1+z(t)^{2}\right)^{\alpha_{2}}, \quad z(0)=2+U_{0} .
$$

Obviously, $u(t)<z(t)$ for $0 \leqq t<\min \left\{t_{\max }, \sigma_{2}\left(d_{2}\right)\right\}$. Thus, the lemma is established if we can show that $\sup _{s \geq 0} z(s)<\infty$. The assumption $\alpha=\alpha_{1}+\alpha_{2}>1$ implies

$$
\begin{aligned}
\int_{0}^{t} \frac{\dot{z}(s)}{\left(1+z(s)^{2}\right)^{\alpha_{2}}} d s & =2^{\alpha_{2}} K_{1} \int_{0}^{t}(1+s)^{-\alpha} d s \\
& \leqq 2^{\alpha_{2}} K_{1} \int_{0}^{\infty}(1+s)^{-\alpha} d s<\infty
\end{aligned}
$$

On the other hand,

whence

$$
\int_{0}^{t} \frac{\dot{z}(s)}{\left(1+z(s)^{2}\right)^{\alpha_{2}}} d s=\int_{z(0)}^{z(t)} \frac{d z}{\left(1+z^{2}\right)^{\alpha_{2}}}
$$

$$
\int_{z(0)}^{\sup _{t \geq 0} z(t)} \frac{d z}{\left(1+z^{2}\right)^{\alpha_{2}}}<\infty .
$$

Because of the assumption $\alpha_{2} \leqq 1 / 2$ this entails $\sup z(t)<\infty$, and the proof is complete. 
For the rest of this section assume that $\left(\stackrel{\circ}{\mathrm{K}}, \stackrel{\circ}{f}_{f}\right) \in \mathscr{D}$ with $d_{2}<\varepsilon_{2}$ so that Theorem 2 and Lemma 5.1 apply.

The Free Streaming Condition. Let us make precise what we mean by saying that a solution $\left(f, K_{f}\right)$ behaves almost like a free streaming. To this end choose $\beta \in] 1 / 2, \min \left\{\alpha_{1}, \alpha / 2,3 / 4\right\}\left[\right.$, where $\alpha=\alpha_{1}+\alpha_{2}$.

Definition 5.2. Let $\left(f, K_{f}\right)$ be a classical solution of $\mathrm{RVM}, 0 \leqq a<b \leqq T\left(f, K_{f}\right)$ and $\eta>0$. The solution $\left(f, K_{f}\right)$ satisfies condition (FS) with respect to the constant $\eta$ on the interval $[a, b[$, if the estimates

$$
\begin{gathered}
\left|K_{f}(t, x)\right| \leqq \eta\left(1+R_{0}+t+|x|\right)^{-\beta}\left(1+R_{0}+t-|x|\right)^{-\beta}, \\
\left|\partial_{x} K_{f}(t, x)\right| \leqq \eta\left(1+R_{0}+t+|x|\right)^{-\beta}\left(1+R_{0}+t-|x|\right)^{-\beta-1}
\end{gathered}
$$

hold for $t \in\left[a, b\left[\right.\right.$ and $x \in \mathbb{R}^{3}$ with $|x| \leqq R_{0}+t$.

For $\eta$ small enough we obtain the following estimates for the support of the function $f(t)$ on the interval $[a, b[$ :

Lemma 5.3. There is a constant $\eta_{1}>0$ such that if a solution $\left(f, K_{f}\right)$ satisfies condition (FS) with respect to a constant $\eta \leqq \eta_{1}$ on an interval $\left[a, b\left[\subset\left[0, T\left(f, K_{f}\right)[\right.\right.\right.$ with $a \leqq \sigma_{2}\left(d_{2}\right)$, then

$$
\operatorname{supp} f(t) \subset\left\{(x, v) \in \mathbb{R}^{6}|| x\left|\leqq R_{0}+\hat{C}_{1} t,\right| v \mid \leqq C_{1}\right\}, \quad 0 \leqq t<b,
$$

where $C_{1}:=2 c_{1}$ and $\hat{C}_{1}:=C_{1}\left(1+C_{1}^{2}\right)^{-1 / 2}$.

Proof. Let $\eta>0$ be arbitrary. For $t \in\left[0, \sigma_{2}\left(d_{2}\right)\right]$ the claim follows from Lemma 5.1 with $c_{1}$ instead of $C_{1}$. For $(x, v) \in \operatorname{supp} f$ define

$$
\tilde{t}:=\sup \left\{t \in \left[a, b\left[|| V_{f}(s, 0, x, v) \mid \leqq C_{1}, s \in[0, t]\right\} .\right.\right.
$$

The assumption $a \leqq \sigma_{2}\left(d_{2}\right)$ implies $\tilde{t}>a$, and on the interval [a, $\tilde{t}[$ we obtain

$$
\left|X_{f}(t, 0, x, v)\right| \leqq R_{0}+\int_{0}^{t}\left|\hat{V}_{f}(s, 0, x, v)\right| d s \leqq R_{0}+\hat{C}_{1} t
$$

Now (FS) implies

$$
\begin{aligned}
\left|K_{f}\left(t, X_{f}(t)\right)\right| & \leqq \eta\left(1+R_{0}+t+\left|X_{f}(t)\right|\right)^{-\beta}\left(1+R_{0}+t-\left|X_{f}(t)\right|\right)^{-\beta} \\
& \leqq \eta(1+t)^{-\beta}\left(1+R_{0}+t-R_{0}-\hat{C}_{1} t\right)^{-\beta} \\
& \leqq \eta\left(1-\hat{C}_{1}\right)^{-\beta}(1+t)^{-2 \beta}
\end{aligned}
$$

and hence

$$
\begin{aligned}
\left|V_{f}(t, 0, x, v)\right| & \leqq\left|V_{f}(a, 0, x, v)\right|+\eta\left(1-\hat{C}_{1}\right)^{-\beta} \int_{a}^{t}(1+s)^{-2 \beta} d s \\
& \leqq c_{1}+\eta\left(1-\hat{C}_{1}\right)^{-\beta}(2 \beta-1)^{-1}, \quad a \leqq t<\tilde{t} .
\end{aligned}
$$

Choosing $\eta_{1}:=\frac{1}{2} c_{1}\left(1-\widehat{C}_{1}\right)^{\beta}(2 \beta-1)$ we get $\left|V_{f}(t, 0, x, v)\right| \leqq \frac{3}{2} c_{1}$ on the interval $[a, \tilde{t}[$, which by definition of $\tilde{t}$ entails $\tilde{t}=b$ and the proof is complete.

To further exploit condition (FS) we need the following Gronwall lemma for second order differential inequalities: 
Lemma 5.4. Assume that $c_{1}, c_{2} \in C^{-}([a, \infty[)$ with

$$
I:=\int_{a}^{\infty}\left(\sigma c_{1}(\sigma)+c_{2}(\sigma)\right) d \sigma<\infty,
$$

$c_{3}, c_{4} \geqq 0$ and $x \in C^{2}([a, t])$ with $x(t)=\dot{x}(t)=0$ and

$$
|\ddot{x}(s)| \leqq c_{1}(s)\left(|x(s)|+(t-s) c_{3}+c_{4}\right)+c_{2}(s)\left(|\dot{x}(s)|+c_{3}\right)
$$

for $0 \leqq a \leqq s \leqq t<\infty$. Then

$$
|x(s)| \leqq\left((t-s) c_{3}+c_{4}\right) I e^{I}, \quad a \leqq s \leqq t .
$$

Proof. Obviously

$$
x(s)=-\int_{s}^{t} \dot{x}(\tau) d \tau=\int_{s}^{t} \int_{\tau}^{t} \ddot{x}(\sigma) d \sigma d \tau,
$$

whence

$$
|x(s)| \leqq \int_{s}^{t}|\dot{x}(\tau)| d \tau=: z(s) .
$$

Now some straightforward estimates yield

$$
z(s) \leqq \int_{s}^{t}\left(\sigma c_{1}(\sigma)+c_{2}(\sigma)\right) z(\sigma) d \sigma+\left((t-s) c_{3}+c_{4}\right) \int_{s}^{t}\left(\sigma c_{1}(\sigma)+c_{2}(\sigma)\right) d \sigma .
$$

If $a \leqq s^{\prime} \leqq s \leqq t$, then

$$
z(s) \leqq \int_{s}^{t}\left(\sigma c_{1}(\sigma)+c_{2}(\sigma)\right) z(\sigma) d \sigma+\left(\left(t-s^{\prime}\right) c_{3}+c_{4}\right) \int_{s^{\prime}}^{t}\left(\sigma c_{1}(\sigma)+c_{2}(\sigma)\right) d \sigma,
$$

and Gronwall's lemma completes the proof.

The next lemma will be used to estimate the diameter and thus the volume of the support of the function $f(t, x,)^{\circ}$.

Lemma 5.5. There are constants $\left.\left.\eta_{2} \in\right] 0, \eta_{1}\right]$ and $c_{2}>0$ such that if a solution $\left(f, K_{f}\right)$ satisfies condition (FS) with respect to the constant $\eta_{2}$ on an interval $[a, b[\subset$ $\left[0, T\left(f, K_{f}\right)\left[\right.\right.$ with $a \leqq \sigma_{2}\left(d_{2}\right)$, then

$$
\left|X_{f}(s, t, x, v)-X_{f}\left(s, t, x, v^{\prime}\right)\right| \geqq c_{2}(t-s)\left|v-v^{\prime}\right|
$$

for $(x, v),\left(x, v^{\prime}\right) \in \operatorname{supp} f(t)$ and $a \leqq s \leqq t<b$.

Proof. For $(x, v),\left(x, v^{\prime}\right) \in \operatorname{supp} f(t)$ and $a \leqq s \leqq t<b$ define

$$
x(s):=X_{f}(s, t, x, v), \quad \hat{v}(s):=\hat{V}_{f}(s, t, x, v)
$$

and $x^{\prime}(\cdot), \hat{v}^{\prime}(\cdot)$ analogously. One immediately checks that

$$
\ddot{x}(s)=J_{f}(s, x(s), \hat{v}(s)),
$$

where

$$
J_{f}(s, x, \hat{v}):=\sqrt{1-\hat{v}^{2}}\left(E_{f}(s, x)+\hat{v} \times B_{f}(s, x)-\hat{v} \cdot E_{f}(s, x) \hat{v}\right) .
$$

Define

$$
y(s):=x(s)-x^{\prime}(s)+(t-s)\left(\hat{v}-\hat{v}^{\prime}\right), \quad a \leqq s \leqq t<b
$$


to obtain $y(t)=\dot{y}(t)=0$ and

$$
\begin{aligned}
|\ddot{y}(s)|= & \left|\ddot{x}(s)-\ddot{x}^{\prime}(s)\right| \\
= & \left|J_{f}(s, x(s), \hat{v}(s))-J_{f}\left(s, x^{\prime}(s), \hat{v}^{\prime}(s)\right)\right| \\
\leqq & \sup _{0 \leqq \tau \leqq 1}\left|\partial_{x} J_{f}\left(s, \tau x(s)+(1-\tau) x^{\prime}(s), \hat{v}(s)\right)\right|\left|x(s)-x^{\prime}(s)\right| \\
& \quad+\sup _{0 \leqq \tau \leqq 1}\left|\partial_{\hat{v}} J_{f}\left(s, x^{\prime}(s), \tau \hat{v}(s)+(1-\tau) \hat{v}^{\prime}(s)\right)\right|\left|\hat{v}(s)-\hat{v}^{\prime}(s)\right| .
\end{aligned}
$$

A short computation proves

$$
\left|\partial_{x_{k}} J_{f}(s, x, \hat{v})\right| \leqq 2\left|\partial_{x} K_{f}(s, x)\right|, \quad\left|\partial_{\hat{v}_{k}} J_{f}(s, x, \hat{v})\right| \leqq \frac{4}{\sqrt{1-\hat{v}^{2}}}\left|K_{f}(s, x)\right| .
$$

Now take $\left.\eta \in] 0, \eta_{1}\right]$. Since $(x, v) \in \operatorname{supp} f(t)$, and hence $(x(s), v(s)) \in \operatorname{supp} f(s)$, Lemma 5.3 implies

$$
|x(s)| \leqq R_{0}+\hat{C}_{1} s, \quad|v(s)| \leqq C_{1},
$$

for $a \leqq s \leqq t<b$, and analogous estimates hold for $x^{\prime}(s)$ and $v^{\prime}(s)$. Hence

$$
\begin{aligned}
&\left|\tau x(s)+(1-\tau) x^{\prime}(s)\right| \leqq R_{0}+\hat{C}_{1} s \\
&\left|\tau \hat{v}(s)+(1-\tau) \hat{v}^{\prime}(s)\right| \leqq \hat{C}_{1}, \quad 0 \leqq \tau \leqq 1
\end{aligned}
$$

Using condition (FS) we obtain the estimates

$$
\begin{aligned}
& \sup _{0 \leqq \tau \leqq 1}\left|\partial_{x} J_{f}\left(s, \tau x(s)+(1-\tau) x^{\prime}(s), \hat{v}(s)\right)\right| \\
& \quad \leqq C \eta(1+s)^{-\beta}\left(1+R_{0}+s-R_{0}-\hat{C}_{1} s\right)^{-\beta-1} \leqq C \eta(1+s)^{-2 \beta-1}, \\
& \sup _{0 \leqq \tau \leqq 1}\left|\partial_{\hat{v}} J_{f}\left(s, x^{\prime}(s), \tau \hat{v}(s)+(1-\tau) \hat{v}^{\prime}(s)\right)\right| \\
& \quad \leqq \frac{C}{\sqrt{1-\hat{C}_{1}^{2}}} \eta(1+s)^{-\beta}\left(1+R_{0}+s-R_{0}-\hat{C}_{1} s\right)^{-\beta} \leqq C \eta(1+s)^{-2 \beta} .
\end{aligned}
$$

Thus, the function $y$ satisfies

$$
\begin{aligned}
|\ddot{y}(s)| \leqq & C \eta(1+s)^{-2 \beta-1}\left|x(s)-x^{\prime}(s)\right|+C \eta(1+s)^{-2 \beta}\left|\hat{v}(s)-\hat{v}^{\prime}(s)\right| \\
\leqq & C \eta(1+s)^{-2 \beta-1}\left(|y(s)|+(t-s)\left|\hat{v}-\hat{v}^{\prime}\right|\right) \\
& +C \eta(1+s)^{-2 \beta}\left(|\dot{y}(s)|+\left|\hat{v}-\hat{v}^{\prime}\right|\right),
\end{aligned}
$$

and Lemma 5.4 implies

$$
|y(s)| \leqq\left|\hat{v}-\hat{v}^{\prime}\right| \eta I e^{\eta I}(t-s), \quad a \leqq s \leqq t<b,
$$

where

$$
I:=\int_{0}^{\infty}\left(C \sigma(1+\sigma)^{-2 \beta-1}+C(1+\sigma)^{-2 \beta}\right) d \sigma<\infty .
$$

Choose $\left.\left.\eta_{2} \in\right] 0, \eta_{1}\right]$ such that $\eta_{2} I e^{\eta_{2} I}<1 / 2$ to obtain

$$
\left|X_{f}(s, t, x, v)-X_{f}\left(s, t, x, v^{\prime}\right)+(t-s)\left(\hat{v}-\hat{v}^{\prime}\right)\right|=|y(s)|<\frac{1}{2}(t-s)\left|\hat{v}-\hat{v}^{\prime}\right|,
$$


and hence

$$
\left|X_{f}(s, t, x, v)-X_{f}\left(s, t, x, v^{\prime}\right)\right| \geqq \frac{1}{2}(t-s)\left|\hat{v}-\hat{v}^{\prime}\right|
$$

Since

$$
\partial_{\hat{v}_{k}} v_{j}(\hat{v})=\frac{\left(1-\hat{v}^{2}\right) \delta_{k j}+\hat{v}_{k} \hat{v}_{j}}{{\sqrt{1-\hat{v}^{2}}}^{3}}
$$

Lemma 5.3 implies

$$
\left|v-v^{\prime}\right| \leqq \sup _{0 \leqq \tau \leqq 1}\left|\partial_{\hat{v}} v\left(\tau \hat{v}+(1-\tau) \hat{v}^{\prime}\right)\right|\left|\hat{v}-\hat{v}^{\prime}\right| \leqq C\left|\hat{v}-\hat{v}^{\prime}\right|
$$

for $(x, v),\left(x, v^{\prime}\right) \in \operatorname{supp} f(t)$, and

$$
\left|X_{f}(s, t, x, v)-X_{f}\left(s, t, x, v^{\prime}\right)\right| \geqq c_{2}(t-s)\left|v-v^{\prime}\right| .
$$

This completes the proof.

Finally, condition (FS) implies the following estimate for the derivative of $f$ with respect to $x$, which we will need to estimate $\partial_{x} K_{f}$ :

Lemma 5.6. There is a constant $c_{3}>0$ such that if a solution $\left(f, K_{f}\right)$ satisfies condition (FS) with respect to the constant $\eta_{2}$ on an intervall $\left[a, b\left[\subset\left[0, T\left(f, K_{f}\right)[\right.\right.\right.$ with $a \leqq \sigma_{2}\left(d_{2}\right)$, then

$$
\left\|\partial_{x} f(t)\right\|_{\infty} \leqq c_{3}\|f(a)\|_{1, \infty}, \quad t \in[a, b[.
$$

Proof. The equation

$$
f(t, x, v)=f\left(a, X_{f}(a, t, x, v), V_{f}(a, t, x, v)\right), \quad t \geqq a
$$

implies

$$
\begin{aligned}
\partial_{x} f(t, x, v)= & \partial_{x} f\left(a, X_{f}(a, t, x, v), V_{f}(a, t, x, v)\right) \partial_{x} X_{f}(a, t, x, v) \\
& +\partial_{v} f\left(a, X_{f}(a, t, x, v), V_{f}(a, t, x, v)\right) \partial_{x} V_{f}(a, t, x, v),
\end{aligned}
$$

and hence

$$
\left|\partial_{x} f(t, x, v)\right| \leqq\|f(a)\|_{1, \infty}\left(\left|\partial_{x} X_{f}(a, t, x, v)\right|+\left|\partial_{x} V_{f}(a, t, x, v)\right|\right)
$$

for $t \in\left[a, T\left(f, K_{f}\right)\left[\right.\right.$ and $(x, v) \in \mathbb{R}^{6}$. Now proceed similarly to the proof of Lemma 5.5 to estimate the derivatives of the characteristics with respect to $x$. Since

$$
\ddot{X}_{f}(s, t, x, v)=J_{f}\left(s, X_{f}(s), \hat{V}_{f}(s)\right),
$$

we have

$$
\partial_{x_{k}} \ddot{X}_{f}(s)=\partial_{x} J_{f}\left(s, X_{f}(s), \hat{V}_{f}(s)\right) \partial_{x_{k}} X_{f}(s)+\partial_{\hat{v}} J_{f}\left(s, X_{f}(s), \hat{V}_{f}(s)\right) \partial_{x_{k}} \dot{X}_{f}(s) .
$$

From the proof of Lemma 5.5 we recall the estimates

$$
\left|\partial_{x} J_{f}(s, x, \hat{v})\right| \leqq C\left|\partial_{x} K_{f}(s, x)\right|, \quad\left|\partial_{\hat{v}} J_{f}(s, x, \hat{v})\right| \leqq \frac{C}{\sqrt{1-\hat{v}^{2}}}\left|K_{f}(s, x)\right| .
$$

For $(x, v) \in \operatorname{supp} f(t)$ and $0 \leqq s \leqq t<b$ Lemma 5.3 implies

$$
\left|X_{f}(s, t, x, v)\right| \leqq R_{0}+\hat{C}_{1} s, \quad\left|V_{f}(s, t, x, v)\right| \leqq C_{1} .
$$


Define

$$
x(s):=\partial_{x} X_{f}(s, t, x, v)-\mathrm{id}_{\mathbb{R}^{3}}
$$

to obtain

$$
|\ddot{x}(s)| \leqq C(1+s)^{-2 \beta-1}(|x(s)|+1)+C(1+s)^{-2 \beta}|\dot{x}(s)|
$$

and $x(t)=\dot{x}(t)=0$. Thus, for $a \leqq s \leqq t<b$ and $(x, v) \in \operatorname{supp} f(t)$ Lemma 5.4 implies $|x(s)| \leqq C$, and hence

$$
\left|\partial_{x} X_{f}(s, t, x, v)\right| \leqq C+1
$$

To estimate $\partial_{x} V_{f}$ observe that

$$
\begin{aligned}
\partial_{x_{k}} \dot{V}_{f}(s)= & \partial_{x} E_{f}\left(s, X_{f}(s)\right) \partial_{x_{k}} X_{f}(s)+\partial_{x_{k}} \hat{V}_{f}(s) \times B_{f}\left(s, X_{f}(s)\right) \\
& +\hat{V}_{f}(s) \times\left(\partial_{x} B_{f}\left(s, X_{f}(s)\right) \partial_{x_{k}} X_{f}(s)\right),
\end{aligned}
$$

and thus,

$$
\left|\partial_{x} \dot{V}_{f}(s)\right| \leqq C(1+s)^{-2 \beta-1}+C(1+s)^{-2 \beta}\left|\partial_{x} V_{f}(s)\right| .
$$

Integrating this estimate and applying Gronwall's lemma gives the desired estimate for $\partial_{x} V_{f}(s, t, x, v)$ and completes the proof.

Estimates of the Fields. In order to estimate the data terms in Lemma 3.3 and Lemma 3.4 we need the following two technical lemmas:

Lemma 5.7. Assume that $h \in C\left(\mathbb{R}^{3}\right)$ and $k \in\{2,3,4\}$ with

$$
|h(x)| \leqq K_{0}\left(1+R_{0}+|x|\right)^{-k}, \quad x \in \mathbb{R}^{3} .
$$

Then

$$
\begin{aligned}
& \left|\int_{|x-y|=t} h(y) d S_{y}\right| \\
& \quad \leqq 4 \pi K_{0} t \begin{cases}\left(1+R_{0}+t-|x|\right)^{-1}, & \text { in case } k=2 \\
\left(1+R_{0}+t+|x|\right)^{-1}\left(1+R_{0}+t-|x|\right)^{-k+2}, & \text { in case } k=3,4\end{cases}
\end{aligned}
$$

for $t \geqq 0$ and $x \in \mathbb{R}^{3}$ with $|x| \leqq R_{0}+t$.

Proof. Obviously

$$
\begin{aligned}
\left|\int_{|x-y|=t} h(y) d S_{y}\right| & \leqq K_{0} \int_{|x-y|=t}\left(1+R_{0}+|y|\right)^{-k} d S_{y} \\
& =K_{0} t^{2} \int_{|\omega|=1}\left(1+R_{0}+|x+t \omega|\right)^{-k} d S_{\omega} .
\end{aligned}
$$

It is easily seen that

$$
u(x):=\int_{|\omega|=1}\left(1+R_{0}+|x+t \omega|\right)^{-k} d S_{\omega}
$$

depends on $r:=|x|$ only. With abuse of notation we have

$$
u(x)=u(r):=\int_{|\omega|=1}\left(1+R_{0}+|r e+t \omega|\right)^{-k} d S_{\omega},
$$


where $e:=(0,0,1)$, and for $r \leqq R_{0}+t$ this implies

$$
\begin{aligned}
u(r) & =\int_{0}^{2 \pi} \int_{0}^{\pi}\left(1+R_{0}+\sqrt{r^{2}+t^{2}+2 r t \cos \theta}\right)^{-k} \sin \theta d \theta d \phi \\
& =2 \pi \frac{1}{r t} \int_{|t-r|}^{t+r} \frac{\lambda d \lambda}{\left(1+R_{0}+\lambda\right)^{k}} \leqq 2 \pi \frac{1}{r t} \int_{t-r}^{t+r} \frac{d \lambda}{\left(1+R_{0}+\lambda\right)^{k-1}},
\end{aligned}
$$

using the substitution $\lambda=\sqrt{r^{2}+t^{2}+2 r t \cos \theta}$. Straightforward calculations now complete the proof.

Lemma 5.8. Assume that $h \in C_{c}\left(\mathbb{R}^{3}\right)$ with supp $h \subset B_{R_{0}}(0)$. Then

$$
\left|\int_{|x-y|=t} h(y) d S_{y}\right| \leqq 4 \pi\|h\|_{\infty} \min \left\{R_{0}^{2}, t^{2}\right\}
$$

for $x \in \mathbb{R}^{3}$ and $t \geqq 0$.

Proof. Let $1_{B_{R_{0}}(0)}$ be the characteristic function of $B_{R_{0}}(0)$ and $S_{t}(x):=$ $\left\{y \in \mathbb{R}^{3}|| x-y \mid=t\right\}$. Obviously

$$
\begin{aligned}
\left|\int_{|x-y|=t} h(y) d S_{y}\right| & \leqq\|h\|_{\infty} \int_{|x-y|=t} 1_{B_{R_{0}}(0)}(y) d S_{y} \\
& =\|h\|_{\infty} \operatorname{vol}_{2}\left(S_{t}(x) \cap B_{R_{0}}(0)\right) \\
& \leqq\|h\|_{\infty} \min \left\{\operatorname{vol}_{2} S_{t}(x), \operatorname{vol}_{2} S_{R_{0}}(0)\right\} \\
& =4 \pi\|h\|_{\infty} \min \left\{t^{2}, R_{0}^{2}\right\} . \quad \square
\end{aligned}
$$

We are now going to estimate the fields of a solution under the condition that the momenta remain bounded and the volume of the support of $f(t, x, \cdot)$ decays. In the proof of Theorem 3 the perturbed solution will satisfy these conditions on some interval by (FS) and its consequences.

Lemma 5.9. For all constants $C_{1}, C_{2}>0$ there exists a constant $C^{*}>0$ having the following property: If a solution $\left(f, K_{f}\right)$ on an interval $\left[0, b\left[\right.\right.$ with initial data $\left(\stackrel{\circ}{f}, \AA_{f}\right) \in \mathscr{D}$ satisfies

$$
\begin{gathered}
\sup \{|v| \mid(x, v) \in \operatorname{supp} f(t)\} \leqq C_{1}, \quad t \in[0, b[ \\
\operatorname{vol}(\operatorname{supp} f(t, x, \cdot)) \leqq C_{2}(1+t)^{-3}, \quad x \in \mathbb{R}^{3}, \quad t \in[0, b[
\end{gathered}
$$

then

$$
\left|K_{f}(t, x)\right| \leqq C^{*}\left(1+R_{0}+t+|x|\right)^{-1}\left(1+R_{0}+t-|x|\right)^{-1}
$$

for $t \in\left[0, b\left[\right.\right.$ and $x \in \mathbb{R}^{3}$ with $|x| \leqq R_{0}+t$.

Proof. We use the integral representation

$$
E_{f}=E_{f, D}+E_{f, T}+E_{f, S}
$$

from Lemma 3.3 and estimate these terms under the assumptions (i) and (ii). The estimates for $B_{f}$ are completely analogous. 
Estimate for $E_{f, D}$ : Consider $t \geqq 0$ and $x \in \mathbb{R}^{3}$ with $|x| \leqq R_{0}+t$. We have

$$
\begin{aligned}
E_{f, D}(t, x)= & \frac{1}{4 \pi t} \int_{|x-y|=t} \operatorname{curl} \stackrel{\circ}{f}_{f}(y) d S_{y}+\frac{1}{4 \pi t^{2}} \int_{|x-y|=t} E_{f}^{\circ}(y) d S_{y} \\
& +\frac{1}{4 \pi t^{2}} \int_{|x-y|=t} \partial_{x} \dot{E}_{f}(y) \cdot(y-x) d S_{y} \\
& -\frac{1}{t} \int_{|x-y|=t|v| \leqq U_{0}} \int_{0} \frac{\omega+\hat{v}}{1+\omega \cdot \hat{v}} \stackrel{\circ}{f}(y, x) d v d S_{y} \\
= & I_{1}+I_{2}+I_{3}+I_{4} .
\end{aligned}
$$

Since $\left(\stackrel{\circ}{f}, \stackrel{\circ}{K}_{f}\right) \in \mathscr{D}$, Lemma 5.7 applies to the terms $I_{1}, I_{2}, I_{3}$ and gives

$$
\begin{aligned}
& \left|I_{1}\right| \leqq K_{0}\left(1+R_{0}+t+|x|\right)^{-1}\left(1+R_{0}+t-|x|\right)^{-1}, \\
& \left|I_{2}\right| \leqq K_{0} t^{-1}\left(1+R_{0}+t-|x|\right)^{-1}, \\
& \left|I_{3}\right| \leqq K_{0}\left(1+R_{0}+t+|x|\right)^{-1}\left(1+R_{0}+t-|x|\right)^{-1} .
\end{aligned}
$$

On the other hand, $\left|I_{2}\right| \leqq\left\|\stackrel{\circ}{E}_{f}\right\|_{\infty} \leqq C$, and hence

$$
\left|I_{2}\right| \leqq C\left(1+R_{0}+t+|x|\right)^{-1}\left(1+R_{0}+t-|x|\right)^{-1} .
$$

By applying Lemma 5.8 to the term $I_{4}$ we obtain

$$
\left|I_{4}\right| \leqq 4 \pi\left(1-\hat{U}_{0}\right)^{-1} \frac{4 \pi}{3} U_{0}^{3}\left\|f^{0}\right\|_{\infty} t^{-1} \min \left\{R_{0}^{2}, t^{2}\right\} \leqq C(1+t)^{-1} .
$$

Since $f^{\circ}(y, \cdot)=0$ for $|x|<t-R_{0}$ and $|x-y|=t$, and

$$
\left(1+R_{0}+t+|x|\right)^{-1}\left(1+R_{0}+t-|x|\right)^{-1} \geqq C(1+t)^{-1}
$$

for $t-R_{0} \leqq|x| \leqq t+R_{0}$, we get

$$
\left|I_{4}\right| \leqq C\left(1+R_{0}+t+|x|\right)^{-1}\left(1+R_{0}+t-|x|\right)^{-1}, \quad|x| \leqq R_{0}+t .
$$

Thus, for $t \geqq 0$ and $x \in \mathbb{R}^{3}$ with $|x| \leqq R_{0}+t$ we have

$$
\left|E_{f, D}(t, x)\right| \leqq C\left(1+R_{0}+t+|x|\right)^{-1}\left(1+R_{0}+t-|x|\right)^{-1} .
$$

Estimate for $E_{f, T}$ : For $\left(f, K_{f}\right) \in \mathscr{D}$ with $d_{2}<\varepsilon_{2}<1$ and $t \in\left[0, T\left(f, K_{f}\right)[\right.$ we have

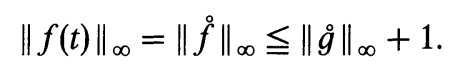

Define

$$
\chi(\tau, \lambda):=\left\{\begin{array}{ll}
1, & \lambda \leqq R_{0}+\tau \\
0, & \lambda>R_{0}+\tau
\end{array} .\right.
$$

For $t \in\left[0, b\left[\right.\right.$ and $x \in \mathbb{R}^{3}$ with $|x| \leqq R_{0}+t$ the assumptions (i) and (ii) together with (5.2) imply

$$
\begin{aligned}
\left|E_{f, T}(t, x)\right| & \leqq \int_{|x-y| \leqq t} \int_{|v| \leqq C_{1}}\left|k_{T}(\omega, v)\right| f(t-|x-y|, y, v) d v \frac{d y}{|x-y|^{2}} \\
& \leqq C \int_{|x-y| \leqq t}(1+t-|x-y|)^{-3} \chi(t-|x-y|,|y|) \frac{d y}{|x-y|^{2}}
\end{aligned}
$$


since $f(\tau, y, \cdot)=0$ for $|y|>R_{0}+\tau$. Now $|y| \leqq R_{0}+t-|x-y|$ entails

$$
(1+t-|x-y|)^{-3} \leqq C\left(1+R_{0}+t-|x-y|+|y|\right)^{-3},
$$

and hence

$$
\left|E_{f, T}(t, x)\right| \leqq C \int_{|x-y| \leqq t}\left(1+R_{0}+t-|x-y|+|y|\right)^{-3} \frac{d y}{|x-y|^{2}} .
$$

Applying [6], Lemma 7 and defining $r:=|x|$ yields

$$
\left|E_{f, T}(t, x)\right| \leqq \frac{C}{r} \int_{0}^{t} \int_{|r-t+\tau|}^{r+t-\tau} \frac{\lambda d \lambda}{\left(1+R_{0}+\tau+\lambda\right)^{3}} \frac{d \tau}{t-\tau} .
$$

Case 1: $r \geqq \frac{1}{2}\left(1+R_{0}+t\right)$

We have

$$
\int_{0}^{t} \int_{|r-t+\tau|}^{r+t-\tau} \frac{\lambda d \lambda}{\left(1+R_{0}+\tau+\lambda\right)^{3}} \frac{d \tau}{t-\tau} \leqq \int_{0}^{t} \int_{|r-t+\tau|}^{r+t-\tau} \frac{d \lambda}{\left(1+R_{0}+\tau+\lambda\right)^{2}} \frac{d \tau}{t-\tau} .
$$

Since

$$
r+t-\tau-|r-t+\tau| \leqq 2(t-\tau)
$$

we may estimate

$$
\begin{aligned}
& \int_{0|r-t+\tau|}^{t} \int_{\mid r+t}^{r+\tau} \frac{d \lambda}{\left(1+R_{0}+\tau+\lambda\right)^{2}} \frac{d \tau}{t-\tau} \leqq 2 \int_{0}^{t} \frac{d \tau}{\left(1+R_{0}+\tau+|r-t+\tau|\right)^{2}} \\
& \quad=2 \int_{0}^{(t-r)+}\left(1+R_{0}+\tau+|r-t+\tau|\right)^{-2} d t+2 \int_{(t-r)_{+}}^{t}\left(1+R_{0}+\tau+|r-t+\tau|\right)^{-2} d \tau \\
& \quad \leqq 2(t-r)_{+}\left(1+R_{0}+t-r\right)^{-2}-\left.\left(1+R_{0}+r-t+2 \tau\right)^{-1}\right|_{(t-r)_{+}} ^{t} \\
& \quad \leqq 3\left(1+R_{0}+t-r\right)^{-1} \leqq 9 r\left(1+R_{0}+t+r\right)^{-1}\left(1+R_{0}+t-r\right)^{-1} .
\end{aligned}
$$

Case 2: $r<\frac{1}{2}\left(1+R_{0}+t\right)$

Since

$$
\lambda(t-\tau)^{-1} \leqq(t+r-\tau)(t-\tau)^{-1} \leqq 2(t-\tau)(t-\tau)^{-1}=2
$$

for $0 \leqq \tau \leqq t-r$ and $\lambda \leqq t+r-\tau$, we get

$$
\begin{aligned}
& \int_{0}^{t} \int_{|r-t+\tau|}^{r+t-\tau} \frac{\lambda d \lambda}{\left(1+R_{0}+\tau+\lambda\right)^{3}} \frac{d \tau}{t-\tau} \\
& \quad=\int_{0}^{(t-r)+r+t-\tau} \int_{t-r-\tau} \frac{\lambda d \lambda}{\left(1+R_{0}+\tau+\lambda\right)^{3}} \frac{d \tau}{t-\tau}+\int_{(t-r)_{+}}^{t} \int_{r-t+\tau}^{r+t-\tau} \frac{\lambda d \lambda}{\left(1+R_{0}+\tau+\lambda\right)^{3}} \frac{d \tau}{t-\tau} \\
& \quad \leqq 2 \int_{0}^{(t-r)+r+t-\tau} \int_{t-r-\tau}^{t} \frac{d \lambda d \tau}{\left(1+R_{0}+\tau+\lambda\right)^{3}}+\int_{(t-r)_{+}}^{t} \int_{t+\tau}^{r+t-\tau} \frac{d \lambda}{\left(1+R_{0}+\tau+\lambda\right)^{2}} \frac{d \tau}{t-\tau} \\
& \quad \leqq 2 \int_{0}^{(t-r)+} 2 r\left(1+R_{0}+\tau+t-r-\tau\right)^{-3} d \tau+2 \int_{(t-r)_{+}}^{t}\left(1+R_{0}+\tau+r-t+\tau\right)^{-2} d \tau \\
& \quad \leqq 6 r\left(1+R_{0}+t-r\right)^{-2} \leqq 18 r\left(1+R_{0}+t+r\right)^{-1}\left(1+R_{0}+t-r\right)^{-1} .
\end{aligned}
$$


Thus

$$
\left|E_{f, T}(t, x)\right| \leqq C\left(1+R_{0}+t+|x|\right)^{-1}\left(1+R_{0}+t-|x|\right)^{-1}
$$

for $t \in\left[0, b\left[\right.\right.$ and $x \in \mathbb{R}^{3}$ with $|x| \leqq R_{0}+t$.

Estimate for $E_{f, s}$ : For $t \in\left[0, b\left[\right.\right.$ and $x \in \mathbb{R}^{3}$ with $|x| \leqq R_{0}+t$ the assumptions (i) and (ii) together with (5.2) imply the following estimate:

$$
\begin{aligned}
\left|E_{f, S}(t, x)\right| & \leqq \int_{|x-y| \leqq t|v| \leqq C_{1}} \int_{S}\left|k_{S}(\omega, v)\left(f L_{f}\right)(t-|x-y|, y, v)\right| d v \frac{d y}{|x-y|} \\
& \leqq C \int_{|x-y| \leqq t} \frac{\chi(t-|x-y|,|y|)}{(1+t-|x-y|)^{3}}\left|K_{f}(t-|x-y|, y)\right| \frac{d y}{|x-y|} \\
& \leqq C \int_{|x-y| \leqq t} \frac{\chi(t-|x-y|,|y|)}{\left(1+R_{0}+t-|x-y|+|y|\right)^{3}}\left|K_{f}(t-|x-y|, y)\right| \frac{d y}{|x-y|}
\end{aligned}
$$

Conclusion. Combining the estimates (5.1), (5.3), and (5.4) and the corresponding estimates for $B_{f}$ yields

$$
\begin{aligned}
\left|K_{f}(t, x)\right| \leqq & C\left(1+R_{0}+t+|x|\right)^{-1}\left(1+R_{0}+t-|x|\right)^{-1} \\
& +C \int_{|x-y| \leqq t} \frac{\chi(t-|x-y|,|y|)}{\left(1+R_{0}+t-|x-y|+|y|\right)^{3}}\left|K_{f}(t-|x-y|, y)\right| \frac{d y}{|x-y|}
\end{aligned}
$$

for $t \in\left[0, b\left[\right.\right.$ and $x \in \mathbb{R}^{3}$ with $|x| \leqq R_{0}+t$, and applying [5], Lemma 11 to this estimate completes the proof.

Estimates for the Derivatives of the Fields. We are now going to estimate the derivatives of the fields of a solution under the condition that the momenta remain bounded, the volume of the support of $f(t, x, \cdot)$ decays, and the derivative of $f(t)$ with respect to $x$ remains bounded. Again, in the proof of Theorem 3 the perturbed solution will satisfy these conditions on some interval by (FS) and its consequences.

Lemma 5.10. For all constants $C_{1}, C_{2}, C_{3}>0$ there is a constant $C^{* *}>0$ having the following property: If $\left(f, K_{f}\right)$ is a solution with initial data $\left(\stackrel{\circ}{f}, \dot{K}_{f}\right) \in \mathscr{D}$ on an interval $[0, b[$ satisfying

$$
\begin{gathered}
\sup \{|v| \mid(x, v) \in \operatorname{supp} f(t)\} \leqq C_{1}, \quad t \in[0, b[, \\
\operatorname{vol}(\operatorname{supp} f(t, x, \cdot)) \leqq C_{2}(1+t)^{-3}, \quad x \in \mathbb{R}^{3}, t \in[0, b[, \\
\left\|\partial_{x} f(t)\right\|_{\infty} \leqq C_{3}, \quad t \in[0, b[
\end{gathered}
$$

then

$$
\left|\partial_{x} K_{f}(t, x)\right| \leqq C^{* *}\left(1+R_{0}+t+|x|\right)^{-1}\left(1+R_{0}+t-|x|\right)^{-7 / 4}
$$

for $t \in\left[0, b\left[\right.\right.$ and $x \in \mathbb{R}^{3}$ with $|x| \leqq R_{0}+t$.

Proof. We use the integral representation from Lemma 3.4 and estimate the different terms under the assumptions (i), (ii), and (iii). We restrict ourselves to the term $\partial_{x} E_{f}$ the estimates for $\partial_{x} B_{f}$ being similar. 
Estimate for $E_{f, D D}$ : By Lemma 3.4 we have

$$
\begin{aligned}
E_{f, D D}(t, x)= & \frac{1}{4 \pi t} \int_{|x-y|=t} \partial_{x_{k}} \operatorname{curl} \stackrel{\circ}{B}_{f}(y) d S_{y}+\frac{1}{4 \pi t^{2}} \int_{|x-y|=t} \partial_{x_{k}} \stackrel{\circ}{E}_{f}(y) d S_{y} \\
& +\frac{1}{4 \pi t^{2}} \int_{|x-y|=t}\left(\partial_{x_{k}} \partial_{x} \stackrel{\circ}{E}_{f}(y)\right) \cdot(y-x) d S_{y} \\
& -\frac{1}{t} \int_{|x-y|=t|v| \leqq U_{0}} \frac{\omega+\hat{v}}{1+\omega \cdot \hat{v}} \partial_{x_{k}} \stackrel{\circ}{f}(y, v) d v d S_{y} \\
& +\frac{1}{t^{2}} \int_{|x-y|=t|v| \leqq U_{0}} \frac{\omega_{k}(\omega+\hat{v})}{\left(1+v^{2}\right)(1+\omega \cdot \hat{v})^{3}} \stackrel{\circ}{f}(y, v) d v d S_{y} \\
& -\frac{1}{t} \int_{|x-y|=t|v| \leqq U_{0}} \frac{\omega_{k}}{1+\omega \cdot \hat{v}} \partial_{v}\left(\frac{(1)+\hat{v}}{1+\omega \cdot \hat{v}}\right)\left(\stackrel{\circ}{\mathrm{f}} \stackrel{\circ}{f}_{f}\right)(y, v) d v d S_{y} \\
= & I_{1}+I_{2}+I_{3}+I_{4}+I_{5}+I_{6} .
\end{aligned}
$$

Consider $t \in\left[0, b\left[\right.\right.$ and $x \in \mathbb{R}^{3}$ with $|x| \leqq R_{0}+t$. Since $\left(f, \stackrel{\circ}{K}_{f}\right) \in \mathscr{D}$, Lemma 5.7 applies to the terms $I_{1}, I_{2}, I_{3}$ and gives

$$
\begin{aligned}
& \left|I_{1}\right| \leqq K_{0}\left(1+R_{0}+t+|x|\right)^{-1}\left(1+R_{0}+t-|x|\right)^{-2} \\
& \left|I_{2}\right| \leqq K_{0} t^{-1}\left(1+R_{0}+t+|x|\right)^{-1}\left(1+R_{0}+t-|x|\right)^{-1} \\
& \left|I_{3}\right| \leqq K_{0}\left(1+R_{0}+t+|x|\right)^{-1}\left(1+R_{0}+t-|x|\right)^{-2}
\end{aligned}
$$

together with $\left|I_{2}\right| \leqq\left\|\partial_{x} \stackrel{\circ}{E}_{f}\right\|_{\infty} \leqq C$ this implies

$$
\left|I_{2}\right| \leqq C\left(1+R_{0}+t+|x|\right)^{-1}\left(1+R_{0}+t-|x|\right)^{-2} .
$$

Applying Lemma 5.8 to the terms $I_{4}, I_{5}, I_{6}$ we obtain

$$
\begin{aligned}
& \left|I_{4}\right| \leqq C t^{-1} \min \left\{1, t^{2}\right\} \leqq C(1+t)^{-1} \\
& \left|I_{5}\right| \leqq C t^{-2} \min \left\{1, t^{2}\right\} \leqq C(1+t)^{-2} \\
& \left|I_{6}\right| \leqq C t^{-1} \min \left\{1, t^{2}\right\} \leqq C(1+t)^{-1}
\end{aligned}
$$

Since $\stackrel{\circ}{f}(y, \cdot)=0$ for $|x|<t-R_{0}$ and $|x-y|=t$, and

$$
\left(1+R_{0}+t+|x|\right)^{-1}\left(1+R_{0}+t-|x|\right)^{-2} \geqq C(1+t)^{-1}
$$

for $t-R_{0} \leqq|x| \leqq t+R_{0}$, we have

$$
\left|E_{f, D D}(t, x)\right| \leqq C\left(1+R_{0}+t+|x|\right)^{-1}\left(1+R_{0}+t-|x|\right)^{-2}
$$

for $t \in\left[0, b\left[\right.\right.$ and $x \in \mathbb{R}^{3}$ with $|x| \leqq R_{0}+t$.

Extimate for $E_{f, R}$ : For $t \in\left[0, b\left[\right.\right.$ and $x \in \mathbb{R}^{3}$ with $|x| \leqq R_{0}+t$ the assumptions (i) and (ii) together with (5.2) imply

$$
\begin{aligned}
\left|E_{f, R}(t, x)\right| & \leqq \int_{|v| \leqq C_{1}} \frac{1}{1+v^{2}} \int_{|\omega|=1}\left|\frac{\omega+\hat{v}}{(1+\omega \cdot \hat{v})^{3}}\right| \omega_{k} d S_{\omega} f(t, x, v) d v \\
& \leqq C(1+t)^{-3}\|f(t)\|_{\infty} \leqq C(1+t)^{-3}
\end{aligned}
$$


and thus,

$$
\left|E_{f, R}(t, x)\right| \leqq C\left(1+R_{0}+t+|x|\right)^{-1}\left(1+R_{0}+t-|x|\right)^{-2} .
$$

Estimate for $E_{f, T s}$ : Lemma 5.9 together with the assumptions (i) and (ii) implies

$$
\begin{aligned}
\left|E_{f, T S}(t, x)\right| \leqq & \int_{|x-y| \leqq t|v| \leqq C_{1}}\left|k_{T s}(\omega, v)\left(f L_{f}\right)(t-|x-y|, y, v)\right| d v \frac{d y}{|x-y|^{2}} \\
\leqq & C \int_{|x-y| \leqq t}(1+t-|x-y|)^{-3} \chi(t-|x-y|,|y|) \\
& \cdot\left(1+R_{0}+t-|x-y|+|y|\right)^{-1} \frac{d y}{|x-y|^{2}} .
\end{aligned}
$$

By the definition of $\chi$ we only have to integrate with respect to $|y| \leqq R_{0}+t-|x-y|$ and since for these $y$ the estimate

$$
(1+t-|x-y|)^{-3} \leqq C\left(1+R_{0}+t-|x-y|+|y|\right)^{-3}
$$

holds, we obtain

$$
\left|E_{f, T S}(t, x)\right| \leqq C \int_{|x-y| \leqq t}\left(1+R_{0}+t-|x-y|+|y|\right)^{-4} \frac{d y}{|x-y|^{2}} .
$$

Now [6], Lemma 7 implies

$$
\begin{aligned}
\left|E_{f, T S}(t, x)\right| & \leqq \frac{C}{r} \int_{0|r-t+\tau|}^{t} \int_{t+\tau}^{r+t} \frac{\lambda d \lambda}{\left(1+R_{0}+\tau+\lambda\right)^{4}} \frac{d \tau}{t-\tau} \\
& \leqq \frac{C}{r}\left(1+R_{0}+t-r\right)^{-1} \int_{0|r-t+\tau|}^{t} \int_{t+\tau}^{r+\tau} \frac{\lambda d \lambda}{\left(1+R_{0}+\tau+\lambda\right)^{3}} \frac{d \tau}{t-\tau} .
\end{aligned}
$$

The remaining integrals has been estimated by

$$
C r\left(1+R_{0}+t+r\right)^{-1}\left(1+R_{0}+t-r\right)^{-1}
$$

when we treated the term $E_{f, T}$. Altogether this yields

$$
\left|E_{f, T S}(t, x)\right| \leqq C\left(1+R_{0}+t+|x|\right)^{-1}\left(1+R_{0}+t-|x|\right)^{-2}
$$

for $t \in\left[0, b\left[\right.\right.$ and $x \in \mathbb{R}^{3}$ with $|x| \leqq R_{0}+t$.

Estimate for $E_{f, T T}$ : First we consider $t \in\left[2, b\left[\right.\right.$ and split $E_{f, T T}$ into two parts,

$$
E_{f, T T}(t, x)=I_{1}+I_{2}
$$

where

$$
\begin{aligned}
& I_{1}:=\oint_{|x-y| \leqq 1|v| \leqq C_{1}} \int_{T T}(\omega, v) f(t-|x-y|, y, v) d v \frac{d y}{|x-y|^{3}}, \\
& I_{2}:=\int_{1 \leqq|x-y| \leqq t|v| \leqq C_{1}} k_{T T}(\omega, v) f(t-|x-y|, y, v) d v \frac{d y}{|x-y|^{3}} .
\end{aligned}
$$

The term $I_{2}$ is estimated as above, using (i), (ii), and [6], Lemma 7; that is,

$$
\left|I_{2}\right| \leqq C \int_{1 \leqq|x-y| \leqq t}(1+t-|x-y|)^{-3} \chi(t-|x-y|,|y|) \frac{d y}{|x-y|^{3}}
$$




$$
\begin{aligned}
\leqq & C \int_{1 \leqq|x-y| \leqq t}\left(1+R_{0}+t-|x-y|+|y|\right)^{-3} \frac{d y}{|x-y|^{3}} \\
\leqq & \frac{C}{r} \int_{0}^{t-1} \int_{|r-t+\tau|}^{r+t-\tau} \frac{\lambda d \lambda}{\left(1+R_{0}+\tau+\lambda\right)^{3}} \frac{d \tau}{(t-\tau)^{2}} \\
= & \frac{C}{r} \int_{0}^{t / 2} \int_{|r-t+\tau|}^{r+t-\tau} \frac{\lambda d \lambda}{\left(1+R_{0}+\tau+\lambda\right)^{3}} \frac{d \tau}{(t-\tau)^{2}} \\
& +\frac{C}{r} \int_{t / 2}^{t-1} \int_{|r-t+\tau|}^{r+t-\tau} \frac{\lambda d \lambda}{\left(1+R_{0}+\tau+\lambda\right)^{3}} \frac{d \tau}{(t-\tau)^{2}} \\
= & : I_{21}+I_{22} .
\end{aligned}
$$

Now

$$
\begin{aligned}
I_{21} & \leqq \frac{C}{r} \frac{4}{t^{2}} \int_{0}^{t / 2} \int_{|r-t+\tau|}^{r+t-\tau}\left(1+R_{0}+\tau+\lambda\right)^{-2} d \lambda d \tau \\
& \leqq C t^{-1}\left(1+R_{0}+t+|x|\right)^{-1}\left(1+R_{0}+t-|x|\right)^{-1} \\
& \leqq C\left(1+R_{0}+t+|x|\right)^{-1}\left(1+R_{0}+t-|x|\right)^{-2},
\end{aligned}
$$

since $t \geqq 2$. Furthermore,

$$
\begin{aligned}
I_{22} & \leqq \frac{C}{r} \int_{t / 2}^{t-1}\left(1+R_{0}+\tau\right)^{-3} \int_{|r-t+\tau|}^{r+t-\tau} \lambda d \lambda \frac{d \tau}{(t-\tau)^{2}} \\
& =\frac{C}{r} \int_{t / 2}^{t-1}\left(1+R_{0}+\tau\right)^{-3} 2 r(t-\tau) \frac{d \tau}{(t-\tau)^{2}} \\
& \leqq C\left(1+R_{0}+t / 2\right)^{-3} \int_{t / 2}^{t-1} \frac{d \tau}{t-\tau} \\
& =C\left(1+R_{0}+t / 2\right)^{-3} \ln t / 2 \\
& \leqq C\left(1+R_{0}+t / 2\right)^{-11 / 4} \\
& \leqq C\left(1+R_{0}+t+|x|\right)^{-1}\left(1+R_{0}+t-|x|\right)^{-7 / 4}
\end{aligned}
$$

Combining the estimates for $I_{21}$ and $I_{22}$ implies

$$
\left|I_{2}\right| \leqq C\left(1+R_{0}+t+|x|\right)^{-1}\left(1+R_{0}+t-|x|\right)^{-7 / 4}
$$

for $t \in\left[2, b\left[\right.\right.$ and $x \in \mathbb{R}^{3}$ with $|x| \leqq R_{0}+t$. Since

$$
\int_{|\omega|=1} k_{T T}(\omega, v) d S_{\omega}=0
$$

the term $I_{1}$ may be estimated as follows:

$$
\left|I_{1}\right| \leqq C \oint_{|x-y| \leqq 1} \int_{|v| \leqq C_{1}} \frac{|f(t-|x-y|, y, v)-f(t-|x-y|, x, v)|}{|x-y|} d v \frac{d y}{|x-y|^{2}} .
$$

Now the assumptions (ii) and (iii) yield

$$
\operatorname{vol}\left(\operatorname{supp} \frac{f(t-|x-y|, y, \cdot)-f(t-|x-y|, x, \cdot)}{|x-y|}\right) \leqq 2 C_{2}(1+t-|x-y|)^{-3}
$$


and

$$
\frac{|f(t-|x-y|, y, v)-f(t-|x-y|, x, v)|}{|x-y|} \leqq\left\|\partial_{x} f(t-|x-y|)\right\|_{\infty} \leqq C_{3},
$$

which for $t \geqq 2$ implies

$$
\begin{aligned}
\left|I_{1}\right| & \leqq C \int_{|x-y| \leqq 1}(1+t-|x-y|)^{-3} \frac{d y}{|x-y|^{2}} \leqq C t^{-3} \int_{|x-y| \leqq 1} \frac{d y}{|x-y|^{2}} \\
& \leqq C\left(1+R_{0}+t+|x|\right)^{-1}\left(1+R_{0}+t-|x|\right)^{-2} .
\end{aligned}
$$

For $t \in[0, \min \{2, b\}[$ we get

$$
\begin{aligned}
\left|E_{f, T T}(t, x)\right| & \leqq C \int_{|x-y| \leqq t}(1+t-|x-y|)^{-3} \frac{d y}{|x-y|^{2}} \\
& \leqq C \int_{|x-y| \leqq 2} \frac{d y}{|x-y|^{2}} \leqq C,
\end{aligned}
$$

and conclude that for $t \in\left[0, b\left[\right.\right.$ and $x \in \mathbb{R}^{3}$ with $|x| \leqq R_{0}+t$ the following estimate holds:

$$
\left|E_{f, T T}(t, x)\right| \leqq C\left(1+R_{0}+t+|x|\right)^{-1}\left(1+R_{0}+t-|x|\right)^{-7 / 4}
$$

Estimate of $E_{f, s s}$ : The assumption (i) yields

$$
E_{f, S S}(t, x)=\int_{|x-y| \leqq t|v| \leqq C_{1}} k_{S S}(\omega, v) S\left(f L_{f}\right)(t-|x-y|, y, v) d v \frac{d y}{|x-y|} .
$$

Now $S f=-L_{f} \cdot \partial_{v} f$ entails

$$
S\left(f L_{f}\right)=(S f) L_{f}+f S L_{f}=-\operatorname{div}_{v}\left(f L_{f}\right) L_{f}+f S L_{f},
$$

and we therefore split $E_{f, S s}$ into two terms obtaining

$$
E_{f, S S}(t, x)=I_{1}+I_{2}
$$

where

$$
\begin{aligned}
& I_{1}:=-\int_{|x-y| \leqq t|v| \leqq C_{1}} \int_{S S}(\omega, v)\left(\operatorname{div}_{v}\left(f L_{f}\right) L_{f}\right)(t-|x-y|, y, v) d v \frac{d y}{|x-y|}, \\
& I_{2}:=\int_{|x-y| \leqq t|v| \leqq C_{1}} \int_{S S}(\omega, v)\left(f S L_{f}\right)(t-|x-y|, y, v) d v \frac{d y}{|x-y|} .
\end{aligned}
$$

To treat the term $I_{1}$ integrate by parts with respect to $v$ and by (i), (ii), Lemma 5.9, and [6], Lemma 7 obtain

$$
\begin{aligned}
\left|I_{1}\right| \leqq & \int_{|x-y| \leqq t|v| \leqq C_{1}}\left|\partial_{v}\left(k_{S S}(\omega, v) L_{f}\right)\left(f L_{f}\right)(t-|x-y|, y, v)\right| d v \frac{d y}{|x-y|} \\
\leqq & C \int_{|x-y| \leqq t} \frac{\chi(t-|x-y|,|y|)}{(1+t-|x-y|)^{3}}\left(1+R_{0}+t-|x-y|+|y|\right)^{-2} \\
& \cdot\left(1+R_{0}+t-|x-y|-|y|\right)^{-2} \frac{d y}{|x-y|}
\end{aligned}
$$




$$
\begin{aligned}
& \leqq C \int_{|x-y| \leqq t} \frac{\chi(t-|x-y|,|y|)}{\left(1+R_{0}+t-|x-y|+|y|\right)^{5}}\left(1+R_{0}+t-|x-y|-|y|\right)^{-2} \frac{d y}{|x-y|} \\
& =\frac{C}{r} \int_{0}^{t} \int_{|r-t+\tau|}^{r+t-\tau} \frac{\chi(\tau, \lambda) \lambda d \lambda d \tau}{\left(1+R_{0}+\tau+\lambda\right)^{5}\left(1+R_{0}+\tau-\lambda\right)^{2}} \\
& \leqq \frac{C}{r} \int_{0}^{t} \int_{|r-t+\tau|}^{r+t-\tau} \frac{\chi(\tau, \lambda) d \lambda d \tau}{\left(1+R_{0}+\tau+\lambda\right)^{4}\left(1+R_{0}+\tau-\lambda\right)^{2}} .
\end{aligned}
$$

Taking $\tau, \lambda$ from the domain of integration satisfying $\chi(\tau, \lambda) \neq 0$ and defining $\xi:=\tau+\lambda, \sigma:=\tau-\lambda$ we obtain $\xi \in[t-r, t+r]$ and $\sigma \in\left[-R_{0}, t-r\right]$. Thus,

$$
\begin{aligned}
\left|I_{1}\right| & \leqq \frac{C}{r} \int_{t}^{t+r} \int_{-R_{0}}^{t-r}\left(1+R_{0}+\xi\right)^{-4}\left(1+R_{0}+\sigma\right)^{-2} d \sigma d \xi \\
& \leqq \frac{C}{r} \int_{t-r}^{t+r}\left(1+R_{0}+\pi\right)^{-3} d \xi \\
& =\frac{C}{r} \frac{2 r\left(1+R_{0}+t\right)}{\left(1+R_{0}+t+r\right)^{2}\left(1+R_{0}+t-r\right)^{2}} \\
& \leqq C\left(1+R_{0}+t+|x|\right)^{-1}\left(1+R_{0}+t-|x|\right)^{-2}
\end{aligned}
$$

To estimate $I_{2}$ observe that

$$
\begin{aligned}
S L_{f} & =\partial_{t} E_{f}+\partial_{x} E_{f} \hat{v}+\hat{v} \times \partial_{t} B_{f}+\partial_{x}\left(\hat{v} \times B_{f}\right) \hat{v} \\
& =\operatorname{curl} B_{f}-4 \pi j_{f}+\partial_{x} E_{f} \hat{v}-\hat{v} \times \operatorname{curl} E_{f}+\partial_{x}\left(\hat{v} \times B_{f}\right) \hat{v}
\end{aligned}
$$

to obtain

$$
\begin{aligned}
\left|I_{2}\right| \leqq & C \int_{|x-y| \leqq t|v| \leqq C_{1}}|f|\left|j_{f}\right|(t-|x-y|, y, v) d v \frac{d y}{|x-y|} \\
& +C \int_{|x-y| \leqq t|v| \leqq C_{1}}|f|\left|\partial_{x} K_{f}\right|(t-|x-y|, y, v) d v \frac{d y}{|x-y|} \\
= & : I_{21}+I_{22} .
\end{aligned}
$$

By (ii) and (5.2) we may estimate

$$
\left\|j_{f}(t)\right\|_{\infty} \leqq C(1+t)^{-3}, \quad t \in[0, b[,
$$

and continuing as above we obtain

$$
\begin{aligned}
\left|I_{21}\right| & \leqq C \int_{|x-y| \leqq t}\left(1+R_{0}+t-|x-y|+|y|\right)^{-6} \frac{d y}{|x-y|} \\
& =\frac{C}{r} \int_{0|r-t+\tau|}^{t+t-\tau}\left(1+R_{0}+\tau+\lambda\right)^{-6} \lambda d \lambda d \tau \\
& \leqq \frac{C}{r} \int_{0}^{t}\left(1+R_{0}+\tau\right)^{-2} \int_{|r-t+\tau|}^{r+t-\tau}\left(1+R_{0}+\tau+\lambda\right)^{-3} d \lambda d \tau .
\end{aligned}
$$


Now

$$
\begin{aligned}
\int_{|r-t+\tau|}^{r+t-\tau}\left(1+R_{0}+\tau+\lambda\right)^{-3} d \lambda & \leqq \frac{1}{2} \frac{\left(1+R_{0}+t+r\right)^{2}-\left(1+R_{0}+t-r\right)^{2}}{\left(1+R_{0}+t+r\right)^{2}\left(1+R_{0}+t-r\right)^{2}} \\
& =\frac{2\left(1+R_{0}+t\right) r}{\left(1+R_{0}+t+r\right)^{2}\left(1+R_{0}+t-r\right)^{2}} \\
& \leqq 2 r\left(1+R_{0}+t+|x|\right)^{-1}\left(1+R_{0}+t-|x|\right)^{-2}
\end{aligned}
$$

yields

$$
I_{21} \leqq C\left(1+R_{0}+t+|x|\right)^{-1}\left(1+R_{0}+t-|x|\right)^{-2} .
$$

Estimating $I_{22}$ we get

$$
I_{22} \leqq C \int_{|x-y| \leqq t} \frac{\chi(t-|x-y|,|y|)}{\left(1+R_{0}+t-|x-y|+|y|\right)^{3}}\left|\partial_{x} K_{f}(t-|x-y|, y)\right| \frac{d y}{|x-y|},
$$

and combining all our estimates for $E_{f, s s}$ we have

$$
\begin{aligned}
\left|E_{f, s s}(t, x)\right| \leqq & C\left(1+R_{0}+t+|x|\right)^{-1}\left(1+R_{0}+t-|x|\right)^{-2} \\
& +C \int_{|x-y| \leqq t} \frac{\chi(t-|x-y|,|y|)\left|\partial_{x} K_{f}(t-|x-y|, y)\right|}{\left(1+R_{0}+t-|x-y|+|y|\right)^{3}} \frac{d y}{|x-y|}
\end{aligned}
$$

for $t \in\left[0, b\left[\right.\right.$ and $x \in \mathbb{R}^{3}$ with $|x| \leqq R_{0}+t$.

Conclusion. Combining the estimates (5.5), (5.6), (5.7), (5.8), and (5.9) and the corresponding estimates for $\partial_{x} B_{f}$ yields

$$
\begin{aligned}
\left|\partial_{x} K_{f}(t, x)\right| \leqq & C\left(1+R_{0}+t+|x|\right)^{-1}\left(1+R_{0}+t-|x|\right)^{-7 / 4} \\
& +C \int_{|x-y| \leqq t} \frac{\chi(t-|x-y|,|y|)\left|\partial_{x} K_{f}(t-|x-y|, y)\right|}{\left(1+R_{0}+t-|x-y|+|y|\right)^{3}} \frac{d y}{|x-y|}
\end{aligned}
$$

for $t \in\left[0, b\left[\right.\right.$ and $x \in \mathbb{R}^{3}$ with $|x| \leqq R_{0}+t$, and applying [5], Lemma 11 to this estimate completes the proof.

We are now ready to prove Theorem 3 .

Proof of Theorem 3. Since $\beta<\min \left\{\alpha_{1}, \frac{1}{2}\left(\alpha_{1}+\alpha_{2}\right)\right\}$ there exists $T_{1}>0$ such that

$$
\begin{gathered}
K_{1}(1+t)^{-\alpha_{1}}\left(1+R_{0}+t-|x|\right)^{-\alpha_{2}} \leqq \frac{\eta_{2}}{3}\left(1+R_{0}+t+|x|\right)^{-\beta}\left(1+R_{0}+t-|x|\right)^{-\beta} \\
K_{1}(1+t)^{-\alpha_{1}}\left(1+R_{0}+t-|x|\right)^{-\alpha_{2}-1} \leqq \frac{\eta_{2}}{3}\left(1+R_{0}+t+|x|\right)^{-\beta}\left(1+R_{0}+t-|x|\right)^{-\beta-1},
\end{gathered}
$$

for $t \geqq T_{1}$ and $x \in \mathbb{R}^{3}$ with $|x| \leqq R_{0}+t$.

Choose $\left.\left.\varepsilon_{3} \in\right] 0, \varepsilon_{2}\right]$ so small that $d_{2}<\varepsilon_{3}$ implies $\sigma_{2}\left(d_{2}\right)>T_{1}$ and

$$
\begin{aligned}
\zeta_{2}\left(T_{1}\right) d_{2} & \leqq \frac{\eta_{2}}{3}\left(1+R_{0}+T_{1}+|x|\right)^{-\beta}\left(1+R_{0}+T_{1}-|x|\right)^{-\beta-1} \\
& \leqq \frac{\eta_{2}}{3}\left(1+R_{0}+T_{1}+|x|\right)^{-\beta}\left(1+R_{0}+T_{1}-|x|\right)^{-\beta}
\end{aligned}
$$


for $x \in \mathbb{R}^{3}$ with $|x| \leqq R_{0}+T_{1}$. Combining the estimates (5.10) and (5.11) and using Theorem 2 and the decay condition (D) gives

$$
\begin{aligned}
\left|K_{f}\left(T_{1}, x\right)\right| & \leqq \frac{2}{3} \eta_{2}\left(1+R_{0}+T_{1}+|x|\right)^{-\beta}\left(1+R_{0}+T_{1}-|x|\right)^{-\beta}, \\
\left|\partial_{x} K_{f}\left(T_{1}, x\right)\right| & \leqq \frac{2}{3} \eta_{2}\left(1+R_{0}+T_{1}+|x|\right)^{-\beta}\left(1+R_{0}+T_{1}-|x|\right)^{-\beta-1}
\end{aligned}
$$

for $|x| \leqq R_{0}+T_{1}$. Hence

$$
\begin{aligned}
T_{2}\left(f, K_{f}\right):=\sup \left\{t \in \left[T_{1}, T\left(f, K_{f}\right)\left[\mid\left(f, K_{f}\right) \text { satisfies }(\mathrm{FS})\right.\right.\right. \\
\text { with respect to } \left.\eta_{2} \text { on }\left[T_{1}, t\right]\right\}>T_{1} .
\end{aligned}
$$

We now estimate the volume of the support of $f(t, x, \cdot)$. Observe that for $(x, v)$, $\left(x, v^{\prime}\right) \in \operatorname{supp} f(t)$ and $t \in\left[T_{1}, T_{2}\left(f, K_{f}\right)\right.$ [, Lemma 5.5 and Lemma 5.3 yield

$$
\begin{aligned}
\left|v-v^{\prime}\right| & \leqq c_{2}\left(t-T_{1}\right)^{-1}\left|X_{f}\left(T_{1}, t, x, v\right)-X_{f}\left(T_{1}, t, x, v^{\prime}\right)\right| \\
& \leqq 2 c_{2}\left(R_{0}+\hat{C}_{1} T_{1}\right)\left(t-T_{1}\right)^{-1},
\end{aligned}
$$

and for $t \in\left[0, T_{2}\left(f, K_{f}\right)\left[\right.\right.$ and $(x, v),\left(x, v^{\prime}\right) \in \operatorname{supp} f(t)$ Lemma 5.3 implies

$$
\left|v-v^{\prime}\right| \leqq 2 C_{1} \text {. }
$$

Hence

$$
\operatorname{diam}(\operatorname{supp} f(t, x, \cdot)) \leqq C(1+t)^{-1},
$$

and there exists a constant $C_{2}>0$ such that for all $\left(f, \AA_{f}^{\circ}\right) \in \mathscr{D}$ with $d_{2}<\varepsilon_{3}$ the estimate

$$
\operatorname{vol}(\operatorname{supp} f(t, x, \cdot)) \leqq C_{2}(1+t)^{-3}, \quad t \in\left[0, T_{2}\left(f, K_{f}\right)\left[, x \in \mathbb{R}^{3}\right.\right.
$$

holds. Furthermore, Lemma 5.3 yields

$$
\sup \{|v| \mid(x, v) \in \operatorname{supp} f(t)\} \leqq C_{1}, \quad t \in\left[0, T_{2}\left(f, K_{f}\right)[.\right.
$$

By Lemma 5.6

$$
\left\|\partial_{x} f(t)\right\|_{\infty} \leqq C\left\|f\left(T_{1}\right)\right\|_{1, \infty}, \quad t \in\left[T_{1}, T_{2}\left(f, K_{f}\right)[,\right.
$$

while Theorem 2 implies

$$
\|f(t)\|_{1, \infty} \leqq\|g(t)\|_{1, \infty}+\zeta_{2}\left(T_{1}\right) d_{2} \leqq C, \quad t \in\left[0, T_{1}\right] .
$$

Thus, there exist constants $C_{1}, C_{2}, C_{3}>0$ such that for $\left(\stackrel{\circ}{f}, \mathscr{K}_{f}\right) \in \mathscr{D}$ with $d_{2}<\varepsilon_{3}$ and $t \in\left[0, T_{2}\left(f, K_{f}\right)[\right.$ the following estimates hold:

$$
\begin{gathered}
\sup \{|v| \mid(x, v) \in \operatorname{supp} f(t)\} \leqq C_{1} \\
\operatorname{vol}(\operatorname{supp} f(t, x, \cdot)) \leqq C_{2}(1+t)^{-3}, \quad x \in \mathbb{R}^{3}, \\
\left\|\partial_{x} f(t)\right\|_{\infty} \leqq C_{3} .
\end{gathered}
$$

We may therefore apply Lemma 5.9 and Lemma 5.10 to obtain constants $C^{*}>0$ and $C^{* *}>0$ such that for all $\left(f, K_{f}\right) \in \mathscr{D}$ with $d_{2}<\varepsilon_{3}, t \in\left[0, T_{2}\left(f, K_{f}\right)\left[\right.\right.$, and $x \in \mathbb{R}^{3}$ with $|x| \leqq R_{0}+t$ we have

$$
\left|K_{f}(t, x)\right| \leqq C^{*}\left(1+R_{0}+t+|x|\right)^{-1}\left(1+R_{0}+t-|x|\right)^{-1} .
$$




$$
\left|\partial_{x} K_{f}(t, x)\right| \leqq C^{* *}\left(1+R_{0}+t+|x|\right)^{-1}\left(1+R_{0}+t-|x|\right)^{-7 / 4} .
$$

Since $\beta<3 / 4<1$ there exists $T_{3}>T_{1}$ such that for $t \geqq T_{3}$ and $x \in \mathbb{R}^{3}$ with $|x| \leqq R_{0}+t$ the following estimates hold:

$$
\begin{aligned}
& C^{*}\left(1+R_{0}+t+|x|\right)^{-1}\left(1+R_{0}+t-|x|\right)^{-1} \\
& \quad \leqq \frac{\eta_{2}}{2}\left(1+R_{0}+t+|x|\right)^{-\beta}\left(1+R_{0}+t-|x|\right)^{-\beta}, \\
& C^{* *}\left(1+R_{0}+t+|x|\right)^{-1}\left(1+R_{0}+t-|x|\right)^{-7 / 4} \\
& \quad \leqq \frac{\eta_{2}}{2}\left(1+R_{0}+t+|x|\right)^{-\beta}\left(1+R_{0}+t-|x|\right)^{-\beta-1} .
\end{aligned}
$$

For $\varepsilon_{3}$ small enough Theorem 2 ensures that $\sigma_{2}\left(d_{2}\right)>T_{3}$ for all $\left(\stackrel{f}{f}, \dot{K}_{f}\right) \in \mathscr{D}$ with $d_{2}<\varepsilon_{3}$ and

$$
\begin{aligned}
\zeta_{2}\left(T_{3}\right) d_{2} & \leqq \frac{\eta_{2}}{3}\left(1+R_{0}+T_{3}+|x|\right)^{-\beta}\left(1+R_{0}+T_{3}-|x|\right)^{-\beta-1} \\
& \leqq \frac{\eta_{2}}{3}\left(1+R_{0}+T_{3}+|x|\right)^{-\beta}\left(1+R_{0}+T_{3}-|x|\right)^{-\beta}
\end{aligned}
$$

for $x \in \mathbb{R}^{3}$ with $|x| \leqq R_{0}+T_{3}$. For $t \leqq T_{3}$ and $x \in \mathbb{R}^{3}$ with $|x| \leqq R_{0}+t$ the monotonicity of $\zeta_{2}$ entails

$$
\begin{aligned}
\zeta_{2}(t) d_{2} & \leqq \frac{\eta_{2}}{3}\left(1+R_{0}+t+|x|\right)^{-\beta}\left(1+R_{0}+t-|x|\right)^{-\beta-1} \\
& \leqq \frac{\eta_{2}}{3}\left(1+R_{0}+t+|x|\right)^{-\beta}\left(1+R_{0}+t-|x|\right)^{-\beta},
\end{aligned}
$$

so that for $T_{1} \leqq t \leqq T_{3}$ and $x \in \mathbb{R}^{3}$ with $|x| \leqq R_{0}+t$ the estimate (5.10) and Theorem 2 imply

$$
\begin{gathered}
\left|K_{f}(t, x)\right| \leqq \frac{2}{3} \eta_{2}\left(1+R_{0}+t+|x|\right)^{-\beta}\left(1+R_{0}+t-|x|\right)^{-\beta} \\
\left|\partial_{x} K_{f}(t, x)\right| \leqq \frac{2}{3} \eta_{2}\left(1+R_{0}+t+|x|\right)^{-\beta}\left(1+R_{0}+t-|x|\right)^{-\beta-1},
\end{gathered}
$$

whence by definition $T_{2}\left(f, K_{f}\right)>T_{3}$. For $t \in\left[T_{3}, T_{2}\left(f, K_{f}\right)\left[\right.\right.$ and $x \in \mathbb{R}^{3}$ with $|x| \leqq R_{0}+t$ the following estimates hold:

$$
\begin{aligned}
\left|K_{f}(t, x)\right| & \leqq C^{*}\left(1+R_{0}+t+|x|\right)^{-1}\left(1+R_{0}+t-|x|\right)^{-1} \\
& \leqq \frac{\eta_{2}}{2}\left(1+R_{0}+t+|x|\right)^{-\beta}\left(1+R_{0}+t-|x|\right)^{-\beta}, \\
\left|\partial_{x} K_{f}(t, x)\right| & \leqq C^{* *}\left(1+R_{0}+t+|x|\right)^{-1}\left(1+R_{0}+t-|x|\right)^{-7 / 4} \\
& \leqq \frac{\eta_{2}}{2}\left(1+R_{0}+t+|x|\right)^{-\beta}\left(1+R_{0}+t-|x|\right)^{-\beta-1} .
\end{aligned}
$$

By definition of $T_{2}\left(f, K_{f}\right)$ this implies $T_{2}\left(f, K_{f}\right)=T\left(f, K_{f}\right)$, and by (5.12) we infer

$$
\sup \{|v| \mid(x, v) \in \operatorname{supp} f(t)\} \leqq C_{1}, \quad 0 \leqq t<T\left(f, K_{f}\right) .
$$

Now Lemma 3.1 yields the desired global existence, the desired estimates for the fields and their derivatives hold by (5.15) and (5.16), and the proof of Theorem 3 is complete. 
As a corollary we note some additional asymptotic results that we obtained in the above proof.

Corollary 5.11. There exist constants $C_{1}>0, C_{2}>0$, and $C_{3}>0$ such that for all initial data $\left(f, K_{f}\right) \in \mathscr{D}$ with $d_{2}<\varepsilon_{3}$ and $t \geqq 0$ the following estimates hold:

$$
\begin{gathered}
\operatorname{supp} f(t) \subset\left\{(x, v) \in \mathbb{R}^{6}|| x\left|\leqq R_{0}+\hat{C}_{1} t,\right| v \mid \leqq C_{1}\right\}, \\
\operatorname{vol}(\operatorname{supp} f(t, x, \cdot)) \leqq C_{2}(1+t)^{-3}, \quad x \in \mathbb{R}^{3}, \\
\left\|\partial_{x} f(t)\right\|_{\infty} \leqq C_{3} .
\end{gathered}
$$

5.2. Global Estimates for the Deviation of the Perturbed from the Unperturbed Solution. Global existence of the perturbed solution being established, the question arises, whether the deviation of $\left(f, K_{f}\right)$ from $\left(g, K_{g}\right)$ can be controlled globally in time. To treat this problem define

$$
\|h\|_{\infty, t}:=\sup _{|x| \leqq R_{0}+t}|h(x)|, \quad h \in C\left(\mathbb{R}^{3}\right), \quad t \geqq 0,
$$

and

$$
\begin{aligned}
& d:=\|\stackrel{\circ}{f}-\stackrel{8}{g}\|_{\infty}+\sup _{x \in \mathbb{R}^{3}}\left(1+R_{0}+|x|\right)^{2}\left|\check{K}_{f}(x)-\check{\circ}_{g}(x)\right| \\
& +\sup _{x \in \mathbb{R}^{3}}\left(1+R_{0}+|x|\right)^{3}\left|\partial_{x} \stackrel{\circ}{K}_{f}(x)-\partial_{x} \stackrel{\circ}{K}_{g}(x)\right| .
\end{aligned}
$$

for $\left(\stackrel{\circ}{f}, \stackrel{\circ}{K}_{f}\right) \in \mathscr{D}$.

Proposition 5.12. Assume that $\left(g, K_{g}\right)$ satisfies (R) and (D). Then there exist constants $C>0$ and $\kappa>0$ such that for all initial data $\left(\stackrel{\circ}{f}, \stackrel{\circ}{K}_{f}\right) \in \mathscr{D}$ with $d_{2}<\varepsilon_{3}$ and $t \geqq 0$ the corresponding solution $\left(f, K_{f}\right)$ satisfies

$$
\begin{aligned}
\left\|K_{f}(t)-K_{g}(t)\right\|_{\infty, t} & \leqq C(1+t)^{\kappa} d, \\
\|f(t)-g(t)\|_{\infty} & \leqq C(1+t)^{\kappa+2} d .
\end{aligned}
$$

Equation (4.1) suggests that we will need an estimate for the derivative of $g$ with respect to $v$ in order to prove Proposition 5.12.

Lemma 5.13. Let $\left(g, K_{g}\right)$ be a solution satisfying the condition (R) and (D). Then there is a constant $C>0$ such that

$$
\left\|\partial_{v} g(t)\right\|_{\infty} \leqq C(1+t), \quad t \geqq 0 .
$$

Proof. Since

$$
g(t, x, v)=\stackrel{g}{g}\left(X_{g}(0, t, x, v), V_{g}(0, t, x, v)\right)
$$

we have

$$
\begin{aligned}
\partial_{v} g(t, x, v)= & \partial_{x} g\left(X_{g}(0, t, x, v), V_{g}(0, t, x, v)\right) \partial_{v} X_{g}(0, t, x, v) \\
& +\partial_{v} \stackrel{\circ}{g}\left(X_{g}(0, t, x, v), V_{g}(0, t, x, v)\right) \partial_{v} V_{g}(0, t, x, v)
\end{aligned}
$$

and obtain

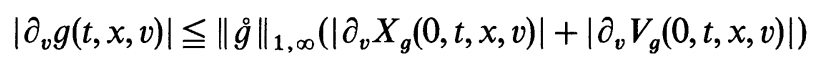

for $t \geqq 0$ and $(x, v) \in \mathbb{R}^{6}$.

With arguments similar to the ones used in the proof of Lemma 5.6 we may 
now estimate the derivatives of the characteristics with respect to $v$. Differentiating

$$
\ddot{X}_{g}(s, t, x, v)=J_{g}\left(s, X_{g}(s), \hat{V}_{g}(s)\right)
$$

with respect to $v$, where

$$
J_{g}(s, x, \hat{v}):=\sqrt{1-\hat{v}^{2}}\left(E_{g}(s, x)+\hat{v} \times B_{g}(s, x)-\hat{v} \cdot E_{g}(s, x) \hat{v}\right),
$$

estimating as in the proof of 5.5 , observing that for $(x, v) \in \operatorname{supp} g(t)$ and $0 \leqq s \leqq t<\infty$ Corollary 5.11 implies

$$
\left|X_{g}(s, t, x, v)\right| \leqq R_{0}+\hat{C}_{1} s, \quad\left|V_{g}(s, t, x, v)\right| \leqq C_{1},
$$

and finally using the assumption (D) we get

$$
|\ddot{x}(s)| \leqq C(1+s)^{-\alpha-1}(|x(s)|+(t-s))+(1+s)^{-\alpha}(|\dot{x}(s)|+1),
$$

where

$$
x(s):=\partial_{v} X_{g}(s, t, x, v)+(t-s) \partial_{v}(\hat{v}(v)) .
$$

Since $x(t)=\dot{x}(t)=0$ and $\alpha=\alpha_{1}+\alpha_{2}>1$, Lemma 5.4 implies

$$
|x(s)| \leqq C(t-s) \text {, }
$$

and hence

$$
\left|\partial_{v} X_{g}(s, t, x, v)\right| \leqq C(t-s) .
$$

On the other hand, we have

$$
\begin{aligned}
\left|\partial_{v} \dot{V}_{g}(s)\right| & \leqq\left|\partial_{x} K_{g}\left(s, X_{g}(s)\right)\right|\left|\partial_{v} X_{g}(s)\right|+\left|B_{g}\left(s, X_{g}(s)\right)\right|\left|\partial_{v} \hat{V}_{g}(s)\right| \\
& \leqq C(1+s)^{-\alpha-1}(t-s)+C(1+s)^{-\alpha}\left|\partial_{v} V_{g}(s)\right| .
\end{aligned}
$$

Integrating this inequality, observing $\left|\partial_{v} V_{f}(t, t, x, v)\right|=1$, and applying Gronwall's lemma yields

$$
\left|\partial_{v} V_{g}(s, t, x, v)\right| \leqq C(1+t) .
$$

Putting the estimates for the derivatives of the characteristics into the estimate for $\partial_{v} g$ completes the proof.

Proof of Proposition 5.12. We use the integral representation from Lemma 3.3 to estimate the difference of the fields. For $t \geqq 0$ and $x \in \mathbb{R}^{3}$ with $|x| \leqq R_{0}+t$ and by the definition of $d$ we obtain the following estimate for the difference of the data terms:

$$
\begin{aligned}
\left|E_{f, D}(t, x)-E_{g, D}(t, x)\right| \leqq & \frac{d}{4 \pi t} \int_{|x-y|=t}\left(1+R_{0}+|y|\right)^{-3} d S_{y} \\
& +\frac{d}{4 \pi t^{2}} \int_{|x-y|=t}\left(1+R_{0}+|y|\right)^{-2} d S_{y} \\
& +C \frac{d}{t} \int_{|x-y|=t} 1_{B_{R_{0}}(0)} d S_{y} .
\end{aligned}
$$

Lemma 5.7 and Lemma 5.8 yield

$$
\left|E_{f, D}(t, x)-E_{g, D}(t ; x)\right| \leqq C d\left(1+R_{0}+t+|x|\right)^{-1}+C d t^{-1}+C d(1+t)^{-1},
$$


and since

$$
\frac{d}{4 \pi t^{2}} \int_{|x-y|=t}\left(1+R_{0}+|y|\right)^{-2} d S_{y} \leqq C d,
$$

we get

$$
\left\|E_{f, D}(t)-E_{g, D}(t)\right\|_{\infty, t} \leqq C(1+t)^{-1} d, \quad t \geqq 0 .
$$

Corollary 5.11 implies that for $t \geqq 0$ and $x \in \mathbb{R}^{3}$ the following estimates hold:

$$
\begin{aligned}
\left|E_{f, T}(t, x)-E_{g, T}(t, x)\right| \leqq & C \int_{|x-y| \leqq t}(1+t-|x-y|)^{-3} \\
& \cdot\|f(t-|x-y|)-g(t-|x-y|)\|_{\infty} \frac{d y}{|x-y|^{2}} \\
= & C \int_{0}^{t}(1+\tau)^{-3}\|f(\tau)-g(\tau)\|_{\infty} d \tau
\end{aligned}
$$

and

$$
\begin{aligned}
& \left|E_{f, S}(t, x)-E_{g, S}(t, x)\right| \\
& \quad \leqq C \int_{|x-y| \leqq t|v| \leqq C_{1}}\left(|f|\left|K_{f}-K_{g}\right|+\left|K_{g}\right||f-g|\right)(t-|x-y|, y, v) d v \frac{d y}{|x-y|} \\
& \quad=: I_{1}+I_{2} .
\end{aligned}
$$

First we estimate the term $I_{1}$ :

$$
\begin{aligned}
I_{1} & \leqq C \int_{|x-y| \leqq t} \frac{\chi(t-|x-y|,|y|)}{(1+t-|x-y|)^{3}}\left|K_{f}-K_{g}\right|(t-|x-y|, y) \frac{d y}{|x-y|} \\
& \leqq C \int_{0}^{t}(1+\tau)^{-3}\left\|K_{f}(\tau)-K_{g}(\tau)\right\|_{\infty, \tau} \tau d \tau \\
& \leqq C \int_{0}^{t}(1+\tau)^{-2}\left\|K_{f}(\tau)-K_{g}(\tau)\right\|_{\infty, \tau} d \tau .
\end{aligned}
$$

To estimate $I_{2}$ define

$$
\tilde{\chi}(\tau, \lambda):= \begin{cases}1, & \lambda \leqq R_{0}+\hat{C}_{1} \tau \\ 0, & \lambda>R_{0}+\hat{C}_{1} \tau\end{cases}
$$

and by Corollary 5.11 and condition (D) obtain that

$$
\begin{aligned}
I_{2} \leqq C \int_{|x-y| \leqq t} \frac{\tilde{\chi}(t-|x-y|,|y|)}{(1+t-|x-y|)^{3+\alpha_{1}}\left(1+R_{0}+t-|x-y|-|y|\right)^{\alpha_{2}}} \\
\quad \cdot\|f(t-|x-y|)-g(t-|x-y|)\|_{\infty} \frac{d y}{|x-y|} .
\end{aligned}
$$

For $|y| \leqq R_{0}+\hat{C}_{1}(t-|x-y|)$ we have

$$
\begin{aligned}
\left(1+R_{0}+t-|x-y|-|y|\right)^{-\alpha_{2}} & \leqq\left(1+\left(1-\hat{C}_{1}\right)(t-|x-y|)\right)^{-\alpha_{2}} \\
& \leqq C(1+t-|x-y|)^{-\alpha_{2}}
\end{aligned}
$$


and thus,

$$
\begin{aligned}
I_{2} & \leqq C \int_{|x-y| \leqq t}(1+t-|x-y|)^{-3-\alpha}\|f(t-|x-y|)-g(t-|x-y|)\|_{\infty} \frac{d y}{|x-y|} \\
& =C \int_{0}^{t}(1+\tau)^{-3-\alpha}\|f(\tau)-g(\tau)\|_{\infty} \tau d \tau \\
& \leqq C \int_{0}^{t}(1+\tau)^{-3}\|f(\tau)-g(\tau)\|_{\infty} d \tau .
\end{aligned}
$$

Hence for $t \geqq 0$ and $|x| \leqq R_{0}+t$

$$
\begin{array}{r}
\left|E_{f, S}(t, x)-E_{g, S}(t, x)\right| \leqq C \int_{0}^{t}(1+\tau)^{-2}\left\|K_{f}(\tau)-K_{g}(\tau)\right\|_{\infty, \tau} d \tau \\
+C \int_{0}^{t}(1+\tau)^{-3}\|f(\tau)-g(\tau)\|_{\infty} d \tau .
\end{array}
$$

Combining the estimates (5.17), (5.18), and (5.19) with the corresponding estimates for $B_{f}-B_{g}$ yields

$$
\begin{aligned}
\left\|K_{f}(t)-K_{g}(t)\right\|_{\infty, t} \leqq & C(1+t)^{-1} d+C \int_{0}^{t}(1+\tau)^{-3}\|f(\tau)-g(\tau)\|_{\infty} d \tau \\
& +C \int_{0}^{t}(1+\tau)^{-2}\left\|K_{f}(\tau)-K_{g}(\tau)\right\|_{\infty, \tau} d \tau
\end{aligned}
$$

Now recall Eq. (4.1):

$$
\begin{aligned}
(f-g)(t, x, v)= & (\stackrel{\circ}{f}-\stackrel{g}{g})\left(X_{f}(0, t, x, v), V_{f}(0, t, x, v)\right) \\
& -\int_{0}^{t}\left(\partial_{v} g \cdot\left(L_{f}-L_{g}\right)\right)\left(s, X_{f}(s, t, x, v), V_{f}(s, t, x, v)\right) d s .
\end{aligned}
$$

If $\left|X_{f}(s, t, x, v)\right|>R_{0}+s$ then $\partial_{v} g\left(s, X_{f}(s), V_{f}(s)\right)=0$, and hence

$$
\left|\left(\partial_{v} g \cdot\left(L_{f}-L_{g}\right)\right)\left(s, X_{f}(s, t, x, v), V_{f}(s, t, x, v)\right)\right| \leqq\left\|\partial_{v} g(s)\right\|_{\infty}\left\|K_{f}(s)-K_{g}(s)\right\|_{\infty, s}
$$

for $(x, v) \in \mathbb{R}^{6}$. For $t \geqq 0$ this implies

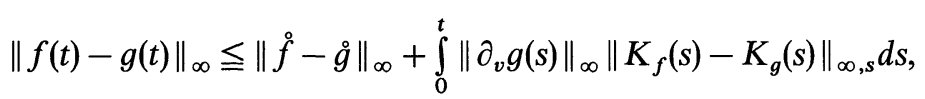

and applying Lemma 5.13 we obtain

$$
\begin{aligned}
& \left\|K_{f}(t)-K_{g}(t)\right\|_{\infty, t} \leqq C(1+t)^{-1} d+C \int_{0}^{t}(1+\tau)^{-3} d \tau\|\stackrel{\circ}{f}-\stackrel{g}{g}\|_{\infty} \\
& +C \int_{0}^{t} \int_{0}^{\tau}(1+\tau)^{-3}(1+\sigma)\left\|K_{f}(\sigma)-K_{g}(\sigma)\right\|_{\infty, \sigma} d \sigma d \tau \\
& +C \int_{0}^{t}(1+\tau)^{-2}\left\|K_{f}(\tau)-K_{g}(\tau)\right\|_{\infty, \tau} d \tau \\
& \leqq C d+C \int_{0}^{t}(1+\tau)^{-2}\left\|K_{f}(\tau)-K_{g}(\tau)\right\|_{\infty, \tau} d \tau \\
& +C \int_{0}^{t} \int_{\sigma}^{t}(1+\tau)^{-2}\left\|K_{f}(\sigma)-K_{g}(\sigma)\right\|_{\infty, \sigma} d \tau d \sigma \\
& \leqq C d+\kappa \int_{0}^{t}(1+\tau)^{-1}\left\|K_{f}(\tau)-K_{g}(\tau)\right\|_{\infty, \tau} d \tau \text {. }
\end{aligned}
$$


Gronwall's lemma now yields

$$
\left\|K_{f}(t)-K_{g}(t)\right\|_{\infty, t} \leqq C \exp \left(\kappa \int_{0}^{t}(1+\tau)^{-1} d \tau\right) d=C(1+t)^{\kappa} d, \quad t \geqq 0 .
$$

Putting this estimate into (5.21) we obtain

$$
\begin{aligned}
\|f(t)-g(t)\|_{\infty} & \leqq\|\stackrel{\circ}{f}-\dot{g}\|_{\infty}+C \int_{0}^{t}(1+s)(1+s)^{\kappa} d s d \\
& \leqq C(1+t)^{\kappa+2} d, \quad t \geqq 0,
\end{aligned}
$$

and the proof is complete.

Remark. The above investigation was of course motivated by the desire to obtain some sort of stability result for solutions satisfying the conditions (R) and (D). Note that if one could establish an estimate like

$$
\left\|\partial_{v} g(t)\right\|_{\infty} \leqq C(1+t)^{\gamma}, \quad t \geqq 0
$$

with $\gamma<1$, the same proof as above would yield

$$
\left\|K_{f}(t)-K_{g}(t)\right\|_{\infty, t} \leqq C d, \quad t \geqq 0,
$$

which might be interpreted as a stability result for the solution $\left(g, K_{g}\right)$.

Acknowledgements. The present paper is an abridged version of the author's doctoral thesis, cf. [12]. He acknowledges with pleasure many helpful conversations with his thesis advisor, Prof.

J. Batt, and with K. Pfaffelmoser.

\section{References}

1. Bardos, C., Degond, P.: Global existence for the Vlasov Poisson equation in 3 space variables with small initial data. Ann. Inst. Henri Poincaré, Analyse non linéaire 2, 101-118 (1985)

2. Batt, J.: Global symmetric solutions of the initial value problem in stellar dynamics. J. Diff. Eqns. 25, 342-364 (1977)

3. Batt, J.: The nonlinear Vlasov-Poisson system of partial differential equations in stellar dynamics. Publications de L.U.E.R. Mathématiques Pures Appliquées, Année 83 5, 1-30 (1983)

4. Glassey, R., Schaeffer, J.: On symmetric solutions of the relativistic Vlasov-Poisson system. Commun. Math. Phys. 101, 459-473 (1985)

5. Glassey, R., Schaeffer, J.: Global existence for the relativistic Vlasov-Maxwell system with nearly neutral initial data. Commun. Math. Phys. 119, 353-384 (1988)

6. Glassey, R., Strauss, W.: Singularity formation in a collisionless plasma could occur only at high velocities. Arch. Rat. Mech. Anal. 92, 59-90 (1986)

7. Glassey, R., Strauss, W.: High velocity particles in a collisionless plasma. Math. Meth. Appl. Sci. 9, 46-52 (1987)

8. Glassey, R., Strauss, W.: Absence of shocks in an initially dilute collisionless plasma. Commun. Math. Phys. 113, 191-208 (1987)

9. Horst, E.: On the classical solutions of the initial value problem for the unmodified non-linear Vlasov equation, Part I and II. Math. Meth. Appl. Sci. 3, 229-248 (1981), 4, 19-32 (1982)

10. Horst, E.: Symmetrical Plasmas and Their Decay. Preprint (1989)

11. Pfaffelmoser, K.: Globale klassische Lösungen des dreidimensionalen Vlasov-Poisson Systems. Ph.D. dissertation, Munich (1989)

12. Rein, G.: Das Verhalten klassischer Lösungen des relativischen Vlasov-Maxwell-Systems bei kleinen Störungen der Anfangsdaten und Aussagen über globale Existenz. Ph.D. dissertation, Munich (1989) 
13. Rein, G.: A two species plasma in the limit of large ion mass. Math. Meth. Appl. Sci. 13, 159-167 (1990)

14. Schaeffer, J.: Global existence for the Poisson-Vlasov system with nearly symmetric data. J. Diff. Eqns. 69, 111-148 (1987)

15. Schaeffer, J.: The classical limit of the relativistic Vlasov-Maxwell system. Commun. Math. Phys. 104, 409-421 (1986)

16. Wollman, S.: An existence and uniqueness theorem for the Vlasov-Maxwell system. Commun. Pure Appl. Math. 37, 457-462 (1984)

Communicated by J. L. Lebowitz 